\title{
Há padrões espaciais de representatividade na câmara municipal do Rio de Janeiro? Análise dos territórios eleitorais dos eleitos em 2008
}

\author{
Are there spatial patterns of representation in council chamber of Rio de Janeiro? \\ Analysis of the electoral territories of the councilors elected in 2008
}

\author{
Sonia Terron* \\ Coordenadora do Espacio ALACIP, Grupo de Pesquisa \\ em Análise Espacial na América Latina, Associação \\ Latinoamericana de Ciência Política, Rua Humaitá \\ 318/504, CEP 22261-001, Rio de Janeiro, RJ, Brasil \\ e-mail: terron.sonia@gmail.com \\ *autor correspondente
}

\section{Andrezza Ribeiro}

Mestranda em Ciência Política, Instituto de Estudos Sociais e Políticos - IESP, Universidade do Estado do Rio de Janeiro - UERJ, Rio de Janeiro, RJ, Brasil e-mail: andrezzarib@gmail.com

\section{Joyce Fonseca Lucas}

Mestranda em Ciência Política, Universidade Federal

Fluminense - UFF, Niterói, RJ, Brasil

e-mail: joyce.fonsecalucas@gmail.com
RESUMO $\mathrm{O}$ artigo analisa a votação dos vereadores eleitos para a Câmara Municipal do Rio de Janeiro em 2008 buscando responder às seguintes questões: (1) há padrões espaciais de votação dos candidatos, (2) é possível classificá-los, e (3) há disputa intrapartidária por território eleitoral. Para respondê-las fazemos uma análise exploratória da conformação geográfica das bases eleitorais utilizando métodos de análise espacial e tomando como unidade espacial de observação os bairros do município. Empregamos a metodologia de Terron (2009) para identificação dos territórios eleitorais, a de Ames (2003) para classificação dos padrões, e propomos um indicador do vínculo candidato - território eleitoral.

PALAVRAS-ChaVe Geografia eleitoral; Eleição municipal; Conexão eleitoral; Autocorrelação espacial.

ABSTRACT This paper analyzes the vote for town councilors elected to the City of Rio de Janeiro in 2008 seeking to answer the following questions: (1) are there spatial patterns of voting for candidates, (2) is it possible to classify them, and (3) is there a dispute by intra-party electoral territory. To answer them we do an exploratory analysis of the geographical conformation of their electoral bases using spatial analysis methods and taking as spatial unit of observation the neighborhoods of the city. We employ the methodology of Terron (2009) to identify the electoral territories, Ames (2003) for pattern classification, and propose an indicator of the bond candidate - electoral territory.

KEYWORDS Electoral geography; Municipal election; The electoral connection; Political parties; Spatial autocorrelation. 


\section{Introdução}

Este artigo tem por finalidade proceder a uma análise exploratória da geografia do voto dos vereadores eleitos no município do Rio de Janeiro em 2008. A Câmara Municipal do Rio de Janeiro encontra-se em sua oitava legislatura, que compreende o período que vai desde as Eleições de 2008 até às Eleições de 2012. O município elegeu, no dia 5 de outubro de 2008, 51 vereadores de 21 partidos $^{1}$. Para tanto investigamos de que maneira se distribuíram os votos dos vereadores eleitos no Rio de Janeiro nas eleições de 2008, e a conformação dos respectivos territórios eleitorais. Procuramos responder a três questões básicas: 1) há padrões espaciais de votação dos candidatos, 2) é possível classificá-los, e 3) há disputa intrapartidária por território eleitoral. Trata-se de um exercício exploratório do emprego de métodos de análise espacial para identificação e caracterização de bases eleitorais em eleições proporcionais, vinculado a discussões relevantes sobre representação política e o sistema de lista aberta.

No contexto das eleições para o legislativo municipal, o Rio de Janeiro opera como um distrito eleitoral de grande magnitude. Nossa hipótese é que abrigue mais padrões de territórios eleitorais concentrados, de natureza local, do que de abrangência municipal. Imagina-se que a diversidade e desigualdade socioespacial do município possa ter reflexos na escolha do vereador, e que predomine padrões onde bairros ou grupos de bairros vizinhos deem preferência a determinados representantes em particular. Ao revelar como os votos destes políticos se distribuem no município, os padrões espaciais que se apresentaram na eleição podem ser identificados, e as disputas pelos territórios eleitorais podem ser indiretamente inferidas. Pretende-se, com isto, subsidiar investigações futuras sobre a relação entre o tipo da base eleitoral e a atuação do parlamentar no exercício da representação política; bem como sobre a existência de relação entre as bases eleitorais e as desigualdades socioespaciais da metrópole, ou seja, sobre o condicionamento de preferências do eleitorado de acordo com condições socioeconômicas locais.

A relação entre a conexão eleitoral e geografia eleitoral dos deputados federais foi analisada por Ames (2003) e Carvalho (2003). Carvalho (2009)

\footnotetext{
Deste total, onze foram afastados. Sendo um por falecimento (Claudinho da Academia - PSDC), um por perda de mandato (Cristiano Girão - PMN), dois por afastamento temporário para assumir cargos na Prefeitura (Cristiane Brasil - PTB, Luiz Antonio Guaraná-PSDB), e sete por renúncia para assumir cargo de deputado federal ou estadual, ganho nas eleições de 2010 (Alfredo Sirkis e Aspásia Camargo - PV, Clarissa Garotinho - PMDB, Liliam Sá - PR, Lucinha - PSDB, Marcio Pacheco - PSC e Stepan Nercessian - PPS).
}

prosseguiu nesta linha de investigação e analisou a geografia eleitoral dos deputados federais nas áreas urbanas e metropolitanas. Encontrou um padrão predominantemente concentrado que, segundo ele, pode desafiar supostos tradicionais de nossa sociologia eleitoral.

Ora, se sabemos pela literatura voltada à análise da conexão eleitoral que a extração concentrada, numa ponta, gera comportamento paroquial, na outra ponta, poderíamos estar diante de fenômeno novo, não previsto pelo otimismo da velha sociologia eleitoral: um paroquialismo com base urbana. É de esperar que a ausência de temas metropolitanos da agenda pública tenha por raiz o que podemos chamar de paroquialismo metropolitano. (Carvalho, 2009: 381). [...] Em síntese, ao lado da análise da disjuntiva rural/ urbano e interior/capital, o eixo que tem nas extremidades um padrão concentrado e outro disperso de distribuição dos votos no espaço geográfico, está na raiz, respectivamente, do paroquialismo e do universalismo legislativos. (Carvalho, 2009: 373).

Até o momento desconhecemos estudo semelhante para o cargo de vereador. Ao identificar os territórios eleitorais dos vereadores, e analisar o conjunto dos territórios de representantes de um mesmo partido, pretende-se contribuir também para a discussão sobre a disputa intrapartidária no sistema de lista aberta. Será que os candidatos disputam os mesmos votos com seus concorrentes de legenda? Haveria uma concentração de votos em determinadas áreas, ocasional ou resultante de estratégia partidária, de modo a evitar disputas entre candidatos do mesmo partido?

O sistema de lista aberta é alvo de críticas por ser um sistema que permite ao eleitor escolher seu candidato, não havendo uma lista pré-ordenada pelo partido pelo qual concorre e por não permitir que os partidos tenham o controle sobre os candidatos que serão eleitos. Assim, estimulariam o voto pessoal evitando a dependência dos partidos. É visto ainda como permissivo ao estimular as disputas intra e interpartidárias, já que os candidatos disputam as vagas entre si. (Nicolau, 2006). Nesta análise vamos explorar a questão do ponto de vista territorial, ou seja, se os candidatos de um mesmo partido tendem a disputar os mesmos territórios eleitorais, e qual a abrangência geográfica das bases eleitorais dos grandes partidos.

Além da discussão da conexão eleitoral e da disputa intrapartidária, a análise exploratória pode subsidiar outra discussão que está na raiz da geografia eleitoral, e diz respeito aos efeitos da interação 
social, da vizinhança, e do contexto geográfico sobre o comportamento eleitoral. Qual a possibilidade do poder legislativo revelar a mesma fragmentação socioespacial do tecido urbano do Rio de Janeiro? Em que medida a diversidade socioespacial se reflete na constituição dos territórios eleitorais dos vereadores cariocas? Por que um candidato ou um partido político tende a receber apoio eleitoral em determinada área da cidade e não em outra? $\mathrm{O}$ que mais influencia no momento da votação, os determinantes sociais ou os determinantes geográficos? Em que medida o contexto determina o voto? Este amplo conjunto de perguntas não será objeto de investigação neste estudo, entretanto, conhecer as características peculiares o município do Rio de Janeiro é necessário para contextualizar a análise proposta.

O município do Rio de Janeiro é um municípiocidade, ou seja, um município sem área rural. Segunda metrópole global do país, a megacidade divide-se administrativamente em cinco grandes áreas de planejamento, trinta e três regiões administrativas e cento e sessenta bairros (IPP, 2012). No mês de outubro de 2008, o seu eleitorado era de 4.562.225, o que corresponde a $40,6 \%$ de todos os eleitores do estado do Rio de Janeiro (TSE, 2008).

O Rio de Janeiro é um modelo para o restante do país, embora sofra com inúmeras situações problemáticas. Com um tecido urbano único e diversificado, seu espaço condiz com uma malha fragmentada que amarga com altos índices de violência e desigualdades de todos os tipos. Assim como tantas outras grandes metrópoles, o Rio de Janeiro é uma cidade social e territorialmente desigual, que evidencia diferentes clivagens socioespaciais.

A crescente fragmentação do tecido urbano veio sendo construída ao longo da trajetória histórico-geográfica do Rio de Janeiro. As áreas que correspondem à zona sul e o centro-leste são as que apresentam maiores oportunidades aos seus moradores. Já a extensão que vai da zona norte à zona noroeste as oferecem de maneira inadequada e insuficiente. Isto porque os valores foram distribuídos irregularmente. As variedades do cenário carioca replicam uma visão dualista que mostra o embate entre cidade e favela ou entre a área central, que é coesa, e a área periférica, que é abandonada. (Martins, 2011)

Martins (2011) empregou métodos de análise espacial para estudar o Rio de Janeiro e investigou indicadores socioeconômicos e de infraestrutura domiciliar nas regiões administrativas, bairros e setores censitários, além da clivagem cidade formal e favelas. Segundo Martins (2011: 132), com base em dados do Censo 2000, as favelas, presentes em todo o território da cidade, abrigam um quinto da população do município, convivem com densidade demográfica 5 vezes mais alta e carências de serviços básicos de 3,5 a 4 vezes maior que na cidade formal. Os chefes de família têm, em média, 4 anos a menos de estudo e renda 4 vezes menor.

Os mapas da Figura 1, elaborados por Martins (2011: 89) apresentam a distribuição da renda média domiciliar per capita e média de anos de estudo dos responsáveis por domicílios nos bairros, segundo o Censo 2010. Mostram claramente a divisão do município. Os intervalos das classes são estabelecidos em intervalos de desvio-padrão: quanto mais vermelha a classe, mais distante e acima da média (em todos os bairros) está o indicador de renda ou de anos de estudo do bairro em questão. Inversamente, quanto mais azul, mais distante e abaixo da média.

Neste cenário de fragmentação socioespacial se desenrolam simultaneamente ações na área de segurança pública, para a retomada dos territórios do tráfico nas grandes favelas, e a chegada de grandes investimentos e obras de preparação para a sequência dos megaeventos que ocorrerão nos próximos anos: Copa das Confederações em 2013, Copa do Mundo em 2014, Copa América em 2015, e Jogos Olímpicos em 2016. Num município com 4,5 milhões de eleitores, os vereadores têm poder bem maior que nos municípios menos populosos. Além do porte das questões de que tratam no exercício do mandato, podem dominar territórios eleitorais significativos para que se mantenham no cargo por muitos mandatos. De acordo com a força de seus territórios eleitorais urbanos podem, e não raro o fazem, galgar outros cargos no executivo ou legislativo, além de fazer a diferença na campanha de seus candidatos em eleições estaduais e nacionais. É neste contexto que surge o interesse por investigar a vereança carioca.

A seção seguinte apresenta os aspectos conceituais e metodológicos relevantes para este estudo. $\mathrm{Na}$ subsequente encontra-se a análise dos padrões geoespaciais da votação dos 51 vereadores da $8^{\circ}$ Legislatura da Câmara Municipal do Rio de Janeiro. Na última seção fazemos um balanço dos "principais achados" e algumas considerações finais.

\section{Aspectos Conceituais e Metodológicos}

Nosso estudo se sustenta nas discussões conceituais e nos métodos de investigação adotados em Terron (2009) e Ames (2003). Terron (2009: 16) analisa a dinâmica socioespaciais da base territorial de Lula e a composição de territórios eleitorais nas eleições presidenciais brasileiras no período de 1989 a 2006. Utiliza análise geoespacial de dados para identificar os territórios eleitorais com base no índice da 


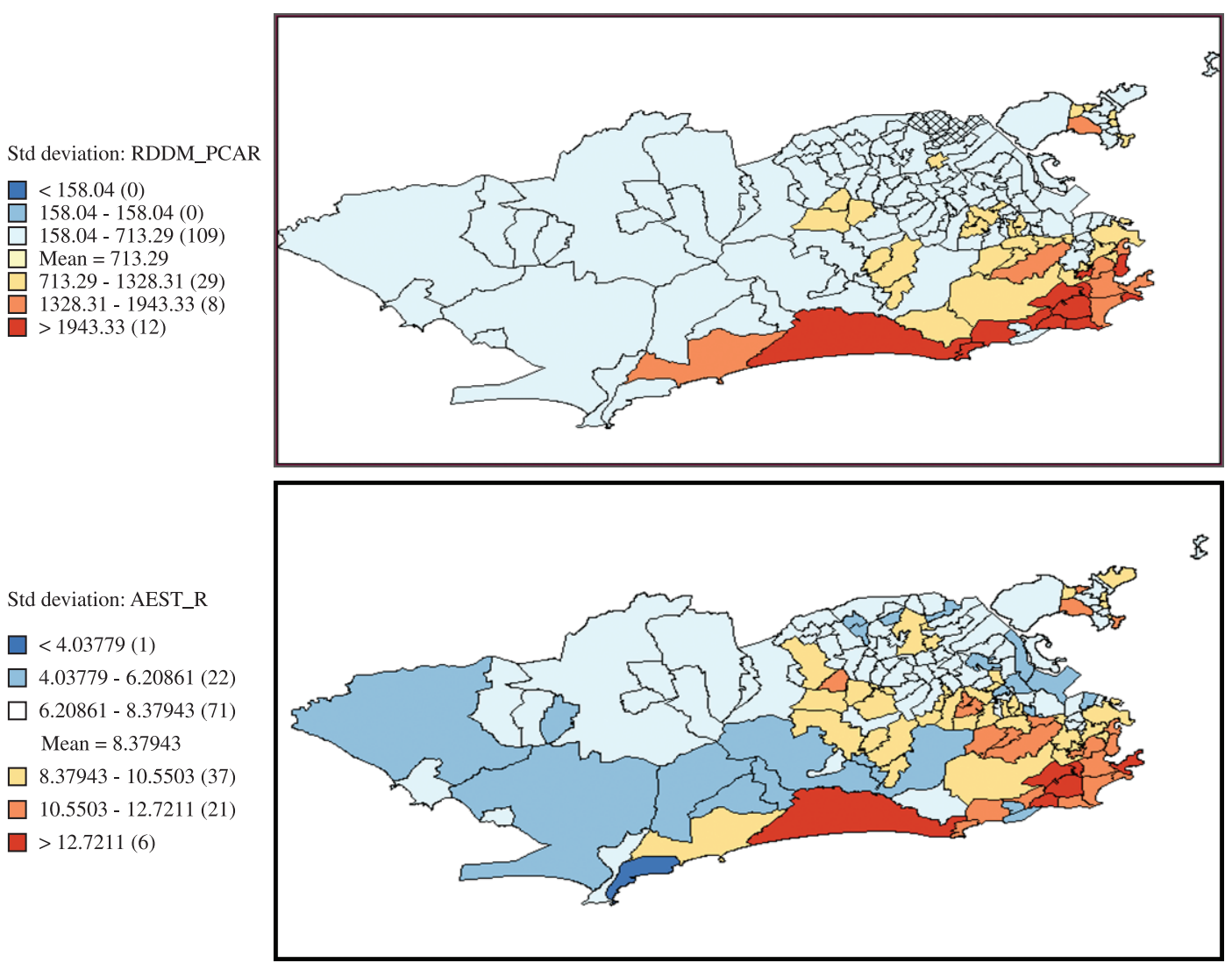

Figura 1. Mapas de desvio padrão da renda média domiciliar per capita e da média de anos de estudo dos responsáveis por domicílio nos Bairros do Rio de Janeiro.

autocorrelação espacial do percentual de votos de cada candidato nos municípios brasileiros.

Antes comenta sobre o emprego em abundância do termo base eleitoral na literatura sobre o comportamento político-eleitoral, e sobre a dificuldade em encontrar referências a parâmetros para que se possa delimitar e dimensionar uma base eleitoral em pesquisas empíricas. Estabelece o território eleitoral como o componente espacial da base eleitoral - um construto que permite localização, caracterização e dimensionamento. Vai buscar fundamentação na conceituação de territórios e territorialidades mais recentemente discutida na geografia, na qual os territórios são "[...] construídos e desconstruídos continuamente pela ação de indivíduos ou grupos que exercem algum tipo de domínio ou poder em determinada área" (Terron, 2009: 54).

O termo base eleitoral é frequentemente empregado como referência a grupos de eleitores que apoiam, sistematicamente, determinado partido ou candidato, e que são identificados pelo local onde vivem, por características socioeconômicas semelhantes, ou por ambos. (Terron, 2009: 51)
A partir desta decisão conceitual, utiliza as estatísticas de autocorrelação espacial, como o Índice de Moran global e local, aplicadas ao percentual de votos de cada candidato nos municípios (unidade espacial de análise do estudo) para a definição dos territórios eleitorais. No nosso caso, as unidades espaciais de análise são os bairros do município do Rio de Janeiro.

A localização, o dimensionamento e a comparação entre as bases eleitorais é feita com base em territórios eleitorais, estruturas constituídas pelo(s) grupamento(s) de municípios onde o candidato recebe percentuais altos de voto e a dependência espacial é significativamente forte entre eles. (Terron 2009: 18)

O índice I de Moran é similar ao coeficiente de correlação de Pearson, e também varia no intervalo entre $(1)$ e $(-1)$. Os valores positivos indicam autocorrelação espacial positiva (clusters), que ocorre quando valores altos ou baixos de determinado local estão associados a valores altos ou baixos, respectivamente, em locais próximos ou vizinhos. Os 
valores negativos sugerem externalidades espaciais (outliers), ou seja, a ocorrência de valores altos cercados por valores baixos nas proximidades, e viceversa. $\mathrm{O}$ valor $(0)$ equivale à hipótese nula do teste, ou seja, a independência espacial (Martins, 2011: 49).

O teste de Moran Local classifica a unidade espacial em quatro categorias: alto-alto, alto-baixo, baixo-alto e baixo-baixo, de acordo com o intervalo de confiança especificado, sendo uma quinta categoria a das unidades não significativas para o teste. As quatro categorias equivalem ao posicionamento da unidade espacial no diagrama de espalhamento de Moran (Moran scatter plot), e são representadas nos mapas de cluster. A primeira referência de alto ou baixo é a dos valores (normalizados) da variável em estudo, na unidade espacial de análise, e a segunda referência de alto e baixo é relativa à média ponderada dessa mesma variável nas unidades espaciais vizinhas. As estatísticas de autocorrelação espacial dependem de uma definição de proximidade para que possam ser calculadas. A tradução entre o conceito de proximidade e a definição da proximidade para o cálculo da autocorrelação é intermediada por uma matriz de vizinhança. Tal como no estudo de Terron (2009), nesta pesquisa utilizamos o critério de adjacência, ou o critério de contiguidade de primeira ordem na construção da matriz de vizinhança².

O estudo de Ames (2003: 61-74) sustenta-se, em uma de suas seções, na taxonomia criada por ele para classificar as bases eleitorais dos deputados federais. Emprega o Índice de Moran da votação percentual dos deputados federais nos municípios para dimensionar a concentração geográfica das bases eleitorais. Combina este índice a um indicador de dominância eleitoral do candidato para criar quatro tipos básicos de distrito informal dos deputados, cada um associado a um padrão distinto de distribuição do voto: concentrado-dominante, concentrado-compartilhado, disperso-dominante e disperso-compartilhado, conforme se observa no quadro da Figura 2, reproduzido de Ames (2003: 65):

\footnotetext{
Sobre autocorrelação espacial, Índice de Moran global e local, e matriz de vizinhança, conferir Smith, Goodchild e Longley (2007) e Terron (2009: 56-68). As estatísticas de Moran são amplamente empregadas na epidemiologia, na criminologia, e mais recentemente na sociologia e geografia urbanas, em especial nos estudos de segregação urbana e desigualdades sociais. Sua utilização nas análises político-eleitorais no Brasil é relativamente pouco difundida. Há diversos outros métodos de análise espacial que podem ser conferidos em Anselin (1999; 2003; 2005), Câmara et al (2002), O'Loughlin (2002), Smith, Goodchild e Longley (2007). Neste estudo as estatísticas de Moran Global e Local são utilizadas para medir a correlação espacial das votações dos vereadores e "descobrir" os territórios eleitorais, com base nos percentuais de voto que os candidatos receberam nos bairros do município do Rio de Janeiro. Para o processamento das estatísticas espaciais foi utilizado o sistema GeoDa.
}

A dimensão da concentração, e seu estado oposto, a dispersão, é medida pelo Índice de Moran, e revela o padrão espacial dos distritos informais. A dimensão da dominância versus o compartilhamento busca identificar se o deputado é mais bem votado e domina os seus municípios principais ou, no extremo oposto, seu melhor desempenho advém de grandes municípios onde ele compartilha os votos com outros candidatos.

Ames (2003) faz uma associação do tipo de votação concentrada e dominante a parlamentares de reduto, de orientação paroquial, que usualmente dominam um grupo de municípios vizinhos. A dominância seria decorrência de várias causas, dentre elas o pertencimento a família de longa proeminência na economia ou política local, ter iniciado a carreira ou ocupado cargos anteriores na região, e ainda, ter feito acordo com caciques locais. (Ames, 2003: 66). O tipo concentrado-compartilhado refere-se ao candidato das capitais e grandes centros urbanos, que têm boa parte de sua votação oriunda destas unidades onde compartilham com muitos outros candidatos o expressivo eleitorado.

Ao tipo disperso-compartilhado associa os parlamentares que conseguem projeção em todo o estado, com menos dependência de redes locais. São aqueles que ganham votos de pequenas faixas do eleitorado de muitos municípios. A sua base de votação pode ter sido construída na ocupação de cargos políticos de expressão estadual ou nacional, ou na mobilização de voto ideológico, religioso ou orientado por questões de interesse de minorias (issue-oriented). O tipo disperso-dominante é associado aos que estabelecem redes de apoio e clientela difusas. Ames (2003: 66) associa este padrão a dois tipos de candidatos: os que fazem acordos com líderes políticos locais, e os que já ocuparam postos burocráticos estaduais e que exerceram políticas distributivas em prol do apoio político de prefeitos e outras lideranças locais. Mesmo que receba altas votações em determinados municípios, não há identificação com aquele eleitorado.

A metodologia de Terron (2009) e de Ames (2003) são empregadas para identificação, dimensionamento e classificação dos territórios eleitorais dos vereadores em estudo neste trabalho. Calculamos o Índice de Moran e o indicador de Dominância de cada vereador. Inserimos um terceiro indicador, o percentual de votos que o candidato recebe nos clusters do tipo alto-alto e alto-baixo, que consideramos como o grau de conexão deste candidato com seu território eleitoral. Os resultados dos três indicadores são analisados individualmente e em conjunto, por candidato e por partido, nas duas seções seguintes.

Os dados utilizados foram organizados a partir dos resultados eleitorais divulgados pelo TRE-RJ relativos 
Padrões estaduais de distribuição espacial

$\%$ do total de votos em municípios principais

\begin{tabular}{|l|c|c|c|}
\cline { 2 - 4 } \multicolumn{1}{c|}{} & Baixa & Alta \\
\cline { 2 - 4 } $\begin{array}{l}\text { Distribuição espacial } \\
\text { de municípios } \\
\text { principais }\end{array}$ & Dispersa & Dispersa-compartilhada & Dispersa-dominante \\
Contígua & Concentrada-compartilhada & Concentrada-dominante \\
\hline
\end{tabular}

Figura 2. Padrões de distribuição do voto proposto por Barry Ames.

à eleição dos vereadores no Rio de Janeiro em 2008. Os votos dos 1149 locais de votação obtidos pelos 51 vereadores eleitos foram agregados nos respectivos bairros, e anexados como tabela de atributos em formato $d b f$ na shapefile de bairros disponibilizada pelo Instituto Municipal de Urbanismo Pereira Passos (IPP, 2012). O software utilizado para elaboração das estatísticas de Moran, dos mapas de cluster e dos diagramas de espalhamento de Moran (Moran Scatterplot) foi o GeoDa, um Sistema de Informação Geográfica $(S I G)$ com funções de estatística espacial ${ }^{3}$.

\section{Análise Geoespacial do Voto por Candidato}

Nesta seção analisamos a votação municipal dos 51 vereadores eleitos em 2008, em relação a: concentração-dispersão geoespacial da votação, medida pelo Índice de Moran dos percentuais de votos recebidos pelo candidato nos bairros; a conexão com o território eleitoral, medida pelo percentual de votos que o candidato recebeu nos bairros de tipo alto-alto e alto-baixo (indicador de Moran Local); e a dominância - compartilhamento da votação, medida pela média da votação recebida nos bairros, ponderada pela contribuição de cada bairro na votação total do

\footnotetext{
Agregação por bairros: Os resultados eleitorais de 2008 para o cargo de vereador no município do Rio de Janeiro foram disponibilizados pelo TSE por seções eleitorais (10.849) agrupadas em 1.149 locais de votação. Para fins desta pesquisa os resultados eleitorais dos locais de votação foram computados aos bairros onde este se situa. A metodologia considera que a discrepância da apuração do voto de eleitores que moram em bairros vizinhos ou que não vivem mais na vizinhança, para o bairro onde se situa o local de votação, não afeta a análise da autocorrelação espacial e consequentemente, a definição dos territórios eleitorais. O Rio de Janeiro tem atualmente 160 bairros. Alguns destes não têm local de votação fisicamente instalados na sua circunscrição, e os eleitores votam nos locais do bairro vizinho. Este é o caso de Campinho, Mangueira, Vista Alegre e Rocinha, cujos votos foram alocados para Praça Seca, São Francisco Xavier, Irajá e São Conrado, respectivamente. Os bairros de Grumari, Joá e Pitangueiras não constavam banco de dados do TSE em 2008. Por estes motivos o total de bairros com resultados eleitorais, utilizado neste trabalho, é menor que os 160 legalmente informados pela Prefeitura.
}

candidato, tal como empregado por Ames (2003), cujo cálculo foi adaptado ao caso em questão:

$$
D_{i}=\sum\left(V_{i x} * M_{i x}\right) / \sum M_{i x}
$$

onde: $\mathrm{i}($ candidatos eleitos $)=1$ a $51 ; \mathrm{x}$ (bairros $)=1 \mathrm{a}$ $160 ;$ Vix $=$ porcentagem dos votos do candidato i no bairro $\mathrm{x}$ em relação ao total de votos para vereador no bairro $\mathrm{x}$

Mix $=$ porcentagem do votos do candidato i no bairro $\mathrm{x}$ em relação ao total de votos no candidato $\mathrm{i}$ no município

As estatísticas (intervalo, valor mínimo, valor máximo, média e desvio padrão), apresentadas no quadro da Figura 3 mostram que os índices de autocorrelação espacial variam em praticamente todo o intervalo positivo ( 0 a 1 ). Vai de 0,025 (Adilson Pires - PT), padrão de ausência de autocorrelação, ou na nossa interpretação, padrão totalmente disperso de votação, a 0,919 (Jorge Pereira-PTdoB), indicando um padrão fortíssimo de concentração. A média ficou em 0,478, com desvio padrão moderado de 0,196 (menos da metade da média).

A votação variou entre 3.200 votos (Marcelo Piuí - PHS) e 68.799 votos (Lucinha - PSDB). A média ficou em 22.900 votos, com desvio padrão um pouco acima de 50\% deste valor (13.509). O território eleitoral de menor peso na votação do candidato contribuiu para apenas 6,5\% de sua votação (Liliam Sá - PR), e o de maior peso contribuiu com $86,2 \%$ dos votos recebidos em todo município (Carminha Jerominho - PTdoB). Em média os territórios eleitorais contribuíram com cerca de $50 \%$ para a votação total dos candidatos, e desvio padrão de $22,6 \%$ (quase metade da média).

A dominância calculada segundo Ames (2003) variou entre 0,3 (Marcelo Piuí - PHS), o padrão mais compartilhado, e 22,2 (Jorge Pereira-PTdoB), o padrão mais dominante. A média é baixa $(4,1)$ e o desvio padrão é mais alto que nos demais casos $(4,2)$, praticamente $100 \%$ da média. O valor máximo muito acima da soma da média e desvio padrão revela uma 
assimetria nesta distribuição, com a presença provável de outliers.

Os respectivos box plots, na Figura 4, mostram que a distribuição do I de Moran é a que mais se aproxima da normal, e que $50 \%$ dos casos se situam entre 0,38 ( $1^{\circ}$ Quartil) e 0,60 ( $3^{\circ}$ Quartil). Com mediana muito próxima da média, se optamos por classificar os casos por uma ou por outra vamos ter aproximadamente $50 \%$ dos casos com concentração alta e a outra metade com concentração baixa. No caso da Dominância, a distribuição é bem diferente: a metade dos vereadores tem dominância até 2,4 (mediana), 46 vereadores tem dominância abaixo de 9 , e 5 vereadores tem dominância acima deste valor, configurando os casos de outliers da distribuição. Neste caso optamos pela média $(4,1)$ para a classificação de dominância alta ou baixa.

No caso da Conexão com o território eleitoral, ou seja, o percentual de votos que o candidato recebeu nos bairros de categoria alto-alto e alto-baixo de Moran local, observa-se a distribuição mais concentrada acima da mediana, e que em $25 \%$ dos casos os territórios eleitorais contribuem com mais de $67 \%$ dos votos do candidato (acima do terceiro Quartil). Média ou mediana fariam pouca diferença na classificação, então mantivemos a média $(50,2 \%)$ como parâmetro de classificação da conexão como alta ou baixa.

Analisamos as correlações de Pearson entre as três dimensões. A correlação entre o I de Moran e o indicador de Dominância é baixa $(0,162)$ e não significativa. Isto significa que os dois indicadores propostos por Ames (2003) para a taxonomia dos padrões são independentes, ou seja, independente da concentração ou dispersão, um padrão pode ser dominante ou disperso. A correlação do indicador de Conexão com o I de Moran é de 0,423 (significativa ao nível de 0,01), e com o indicador de Dominância é de 0,582 (significativa ao nível de 0,01 ). Isto era esperado, uma vez que quanto mais concentrado, mais

Descriptive statistics

\begin{tabular}{|l|r|r|c|c|c|c|}
\hline & $\mathrm{N}$ & Range & Minimum & Maximum & Mean & Std. deviation \\
\hline I_Moran & 51 & 0.894 & 0.024 & 0.919 & 0.47809 & 0.195547 \\
Votos & 51 & 65599 & 3200 & 68799 & $2,29 \mathrm{E} 4$ & 13509,492 \\
Votos_TE & 51 & 57175 & 1017 & 58192 & $1,22 \mathrm{E} 4$ & 10825,638 \\
Conex_TE & 51 & 79,7 & 6,5 & 86,2 & 50,228 & 22,5502 \\
Domin & 51 & 21,9 & 0,3 & 22,2 & 4,147 & 4,1627 \\
Valid N (listwise) & 51 & & & & & \\
\hline
\end{tabular}

Figura 3. Estatísticas descritivas do Índice de Moran, total de votos no município, total de votos no território eleitoral, indicador de conexão com o território eleitoral e indicador de dominância dos 51 vereadores eleitos em 2008 no Rio de Janeiro.
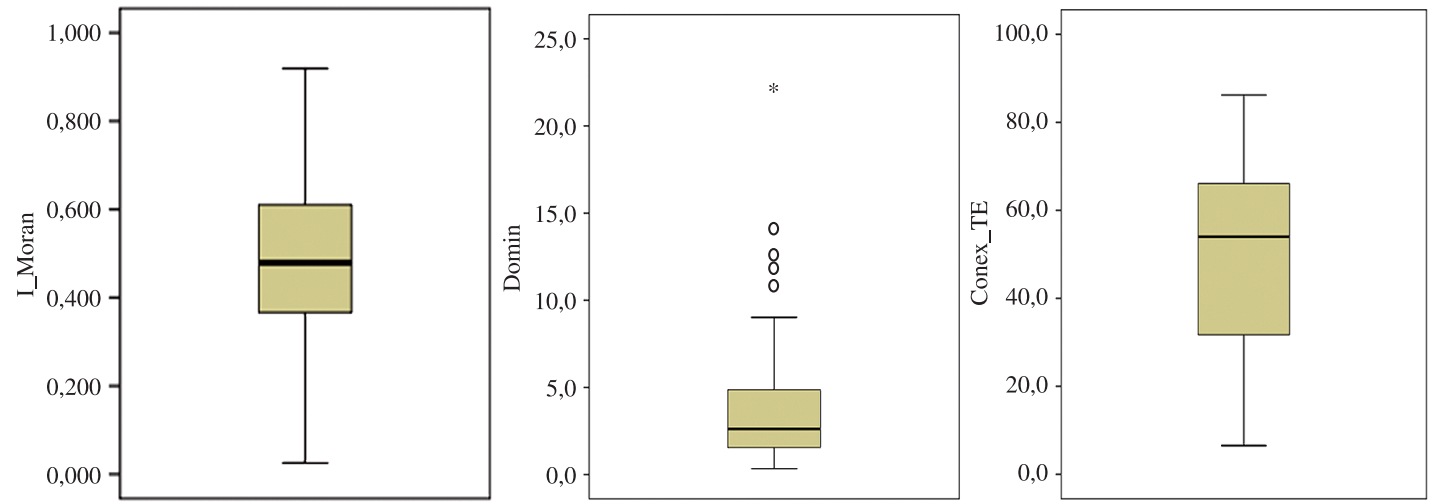

Figura 4. Gráficos do tipo Box Plot do Índice de Moran, do Indicador de Dominância e do Indicador de Conexão com Território Eleitoral. 
probabilidade de que o candidato esteja tirando boa parte de seus votos daquele território; e quanto mais dominante, também. O interessante é ver como estes três indicadores operam combinados, na prática, e se há algum padrão inteligível para o município.

Classificamos os dois indicadores (Concentração e Dominância) em alto e baixo tomando a média da distribuição da respectiva variável como divisor (I de Moran e Índice de Dominância), e reproduzimos a taxonomia de Ames (2003) ${ }^{4}$. As divergências, casos de dominância baixa e conexão alta, e vice-versa, foram reclassificadas no que denominamos de taxonomia adaptada. A Tabela 1 apresenta os três indicadores, as duas classificações, além do total de votos e do partido de cada um dos candidatos eleitos.

A dimensão da dominância e compartilhamento, calculada como na taxonomia de Ames (2003), procura separar os casos em que o candidato recebe o maior peso da sua votação nos bairros onde é mais votado, levando em conta todos os bairros, e vice-versa. Desta forma, equilibra-se na equação o bem votado em bairro de poucos eleitores, e o menos votado proporcionalmente, nos bairros de maior eleitorado. A ponderação pelo percentual da contribuição dos votos do bairro na votação total do candidato, que consta na equação da dominância, faz este papel.

Entretanto, quando agregamos o indicador de conexão com os territórios eleitorais, vemos que há candidatos com concentração geográfica alta, dominância baixa, mas que recebem alto percentual de seus votos do território eleitoral. Consideramos então a possibilidade de que este candidato tenha mais incentivo para preservar seu território e para desenvolver o exercício do mandato com ações de caráter local. Por isto reclassificamos os 9 candidatos que estavam inicialmente classificados como concentrado-compartilhado (tipo 4), para concentrado dominante (tipo 1). Pela mesma lógica, reclassificamos 3 casos que eram dispersocompartilhado (tipo 3), para disperso- dominante (tipo 2). No sentido inverso, reclassificamos dois casos de tipo disperso-dominante (tipo 2). Não houve mudança na classificação do concentrado-compartilhado (tipo 4), que permaneceu igual nas duas taxonomias.

Segundo a taxonomia de Ames (2003), dois terços dos casos são de compartilhamento (concentrados e dispersos), conforme se observa na Tabela 2 . Pela taxonomia adaptada não há uma dimensão predominante. Neste caso, aproximadamente um

\footnotetext{
Como Ames (2003) não explicitou o critério que utilizou para classificação em alto e baixo, não foi possível reproduzir fielmente a taxonomia.
}

terço é concentrado-dominante, um terço é dispersocompartilhado, e o outro terço engloba os outros dois tipos.

Outra observação relevante é que os candidatos mais bem votados tendem para o tipo concentrado, em especial o concentrado-dominante, como se observa na Tabela 1 , apresentada anteriormente. Neste caso, dos 17 candidatos, $70 \%$ têm votação acima da média de 22.900 votos. No caso do concentradocompartilhado, são 33\%. Por outro lado, na dispersão os percentuais são mais baixos: disperso-dominante é $10 \%$; e disperso-compartilhado é $20 \%$.

No quadro da Figura 5 resumimos as informações resultantes desta análise de padrões dos candidatos eleitos. Relacionamos os candidatos segundo a taxonomia adaptada e reproduzimos uma síntese das prováveis características associadas ao tipo segundo a visão de Ames (2003). Estas características foram adaptadas para algo que pudesse ser aplicado aos vereadores. Onde se lia estado, traduzimos para município; e onde se lia município, traduzimos para bairro. Entretanto, este exercício analítico chega até este ponto. Não sabemos se os candidatos apresentam ou não algumas destas características, e em que proporção. Para isto é necessário uma pesquisa sobre a carreira pregressa e a atuação do vereador no exercício do mandato. Nossa intenção é que a análise apresentada sirva de embasamento para uma segunda investigação, a ser realizada posteriormente, que validará ou não as taxonomias aplicadas ao caso dos vereadores cariocas.

\section{Análise Geoespacial do Voto por Partido}

Com o objetivo de verificar se há padrão na disputa intrapartidária entre os vereadores eleitos, vamos analisar os mesmos três indicadores e os mapas de cluster dos candidatos por partido ${ }^{5}$. Selecionamos os sete partidos mais votados dentre os vinte e um (Tabela 3): DEM, PMDB, PSDB, PT, PV, PTdoB e PDT ${ }^{6}$. Nesta seleção estão inclusos partidos com votação concentrada, intermediária e dispersa, como indica o I de Moran calculado com o percentual de votos do partido por bairro.

\footnotetext{
5 Os mapas de cluster apresentam os indicadores de Moran local, ou seja, os bairros são classificados nas cinco categorias: alto-alto (vermelho), alto-baixo (vermelho-claro), baixo-alto (azul claro), baixo-baixo (azul) e não significativo (branco). Os bairros em vermelho e vermelho claro são considerados os territórios eleitorais.

6 DEM: Democratas, PMDB: Partido do Movimento Democrático Brasileiro, PSDB: Partido da Social Democracia Brasileiro, PT: Partido dos Trabalhadores, PV: Partido Verde, PT do B: Partido Trabalhista do Brasil, PDT: Partido Democrático Trabalhista.
} 
Tabela 1. Indicadores de concentração, dominância e conexão, e taxonomias dos vereadores.

\begin{tabular}{|c|c|c|c|c|c|c|c|}
\hline Partido & Candidato (identificação) & $\begin{array}{l}\text { Concentração } \\
\text { (índice de } \\
\text { Moran) }\end{array}$ & Dominância & $\begin{array}{c}\text { Taxonomia } \\
\text { de Ames }\end{array}$ & $\begin{array}{c}\text { Conexão } \\
\text { com } \\
\text { território } \\
\text { eleitoral }\end{array}$ & $\begin{array}{c}\text { Taxonomia } \\
\text { adaptada }\end{array}$ & $\begin{array}{l}\text { Votos no } \\
\text { município }\end{array}$ \\
\hline PSDB & Lucinha (45620) & 0,687 & 12,02 & 1 & 84,58 & 1 & 68.799 \\
\hline DEM & Rosa Fernandes (25625) & 0,715 & 2,70 & 4 & 68,23 & 1 & 64.259 \\
\hline PV & Alfredo Sirkis (43333) & 0,696 & 3,71 & 4 & 54,74 & 1 & 47.729 \\
\hline PMDB & Chiquinho Brazão (15101) & 0,614 & 10,83 & 1 & 75,35 & 1 & 37.845 \\
\hline PMDB & S. Ferraz (15688) & 0,505 & 12,49 & 1 & 75,23 & 1 & 34.546 \\
\hline PTdoB & Jorge Pereira (70633) & 0,919 & 22,20 & 1 & 81,63 & 1 & 33.280 \\
\hline PV & Aspásia Camargo (43123) & 0,761 & 3,83 & 4 & 56,88 & 1 & 31.880 \\
\hline PSDB & Andrea Gouvêa Vieira (45123) & 0,710 & 4,66 & 1 & 61,46 & 1 & 28.213 \\
\hline DEM & Eider Dantas (25678) & 0,579 & 2,89 & 4 & 53,99 & 1 & 27.718 \\
\hline DEM & Aloisio Freitas (25640) & 0,710 & 5,10 & 1 & 60,01 & 1 & 26.545 \\
\hline PMDB & Jorge Felipe (15800) & 0,479 & 2,63 & 4 & 64,41 & 1 & 24.480 \\
\hline PSC & Dr. Jairinho (20126) & 0,608 & 4,29 & 1 & 81,70 & 1 & 23.880 \\
\hline PTdoB & Carminha Jerominho (70670) & 0,482 & 7,17 & 1 & 86,19 & 1 & 22.068 \\
\hline PPS & Paulo Pinheiro (23000) & 0,762 & 1,66 & 4 & 57,75 & 1 & 20.936 \\
\hline PRB & João Mendes de Jesus (10123) & 0,816 & 1,66 & 4 & 83,19 & 1 & 20.005 \\
\hline DEM & Jorge Silva (25105) & 0,669 & 3,89 & 4 & 64,41 & 1 & 18.557 \\
\hline PSOL & Eliomar Coelho (50000) & 0,716 & 1,33 & 4 & 55,11 & 1 & 15.703 \\
\hline PP & Vera Lins (11111) & 0,415 & 5,71 & 2 & 67,75 & 2 & 23.528 \\
\hline PTC & Renato Moura (36500) & 0,291 & 4,65 & 2 & 84,01 & 2 & 18.012 \\
\hline DEM & João Cabral (25101) & 0,410 & 5,79 & 2 & 64,37 & 2 & 17.790 \\
\hline PMDB & Professor Uóston (15633) & 0,421 & 4,11 & 3 & 58,98 & 2 & 14.282 \\
\hline PSB & Rubens Andrade (40603) & 0,207 & 3,79 & 3 & 61,92 & 2 & 11.989 \\
\hline PSDC & Claudinho da Academia (27777) & 0,226 & 14,12 & 2 & 75,70 & 2 & 11.513 \\
\hline PT & Elton Jorge (13444) & 0,454 & 3,91 & 3 & 72,96 & 2 & 11.279 \\
\hline PMN & Cristiano Girão (33123) & 0,253 & 9,03 & 2 & 54,45 & 2 & 10.445 \\
\hline PP & Ivanir de Mello (11211) & 0,380 & 6,25 & 2 & 74,86 & 2 & 6.413 \\
\hline PV & Paulo Messina (43001) & 0,177 & 1,58 & 3 & 52,62 & 2 & 5.201 \\
\hline PSDB & Teresa Bergher (45245) & 0,235 & 8,07 & 2 & 47,98 & 3 & 31.375 \\
\hline PP & Carlos Bolsonaro (11120) & 0,420 & 1,40 & 3 & 23,90 & 3 & 28.209 \\
\hline PSB & Dr. Carlos Eduardo (40044) & 0,127 & 1,25 & 3 & 14,18 & 3 & 27.297 \\
\hline DEM & Tio Carlos (25008) & 0,333 & 2,52 & 3 & 30,98 & 3 & 25.382 \\
\hline PSDB & Luiz Antonio Guaraná(45001) & 0,476 & 2,04 & 3 & 44,64 & 3 & 23.476 \\
\hline PR & Dr. Fernando Moraes (22007) & 0,337 & 1,81 & 3 & 26,71 & 3 & 19.762 \\
\hline PDT & Nereide Pedregal (12787) & 0,157 & 7,70 & 2 & 32,44 & 3 & 19.562 \\
\hline PR & Liliam Sá (22222) & 0,393 & 1,27 & 3 & 6,52 & 3 & 15.742 \\
\hline PTB & Cristiane Brasil (14123) & 0,295 & 1,88 & 3 & 22,42 & 3 & 14.583 \\
\hline
\end{tabular}

Fonte: elaboração dos autores. Notas: A) Ordenação pela taxonomia adaptada e pela ordem decrescente do total de votos; B) Taxonomias: 1 - Concentrado/Dominante, 2 - Disperso/Dominante, 3 - Disperso/Compartilhado, 4 - Concentrado/Compartilhado; C). 
Tabela 1. Continuação...

\begin{tabular}{llcccccc}
\hline Partido & Candidato (identificação) & $\begin{array}{c}\text { Concentração } \\
\text { (índice de } \\
\text { Moran) }\end{array}$ & Dominância & $\begin{array}{c}\text { Taxonomia } \\
\text { de Ames }\end{array}$ & $\begin{array}{c}\text { Conexão } \\
\text { com } \\
\text { território } \\
\text { eleitoral }\end{array}$ & $\begin{array}{c}\text { Taxonomia } \\
\text { adaptada }\end{array}$ & $\begin{array}{c}\text { Votos no } \\
\text { município }\end{array}$ \\
\hline PCdoB & Roberto Monteiro (65123) & 0,402 & 0,89 & 3 & 12,37 & 3 & 14.061 \\
PDT & Jorge Manaia(12580) & 0,358 & 0,51 & 3 & 26,16 & 3 & 14.040 \\
PDT & Leonel Brizola Netto (12345) & 0,398 & 0,53 & 3 & 17,45 & 3 & 12.988 \\
PT & Adilson Pires (13620) & 0,025 & 1,42 & 3 & 8,80 & 3 & 11.555 \\
PRTB & Bencardino (28123) & 0,375 & 1,16 & 3 & 45,51 & 3 & 5.361 \\
PHS & Marcelo Piuí (31031) & 0,373 & 0,35 & 3 & 42,72 & 3 & 3.200 \\
PPS & Stepan Nercessian (23123) & 0,589 & 2,53 & 4 & 42,07 & 4 & 50.532 \\
PMDB & Clarissa Garotinho (15123) & 0,490 & 1,75 & 4 & 12,83 & 4 & 42.062 \\
PSC & Marcio Pacheco (20010) & 0,547 & 1,02 & 4 & 24,38 & 4 & 26.932 \\
PTdoB & Jorge Braz (70070) & 0,703 & 1,98 & 4 & 48,50 & 4 & 23.157 \\
PSDB & Patricia Amorim (45007) & 0,517 & 2,29 & 4 & 46,95 & 4 & 21.140 \\
DEM & Carlo Caiado (25622) & 0,558 & 2,70 & 4 & 44,37 & 4 & 19.042 \\
DEM & Alexandre Cerruti (25123) & 0,563 & 1,59 & 4 & 46,49 & 4 & 17.172 \\
PRB & Tânia Bastos (10789) & 0,502 & 1,32 & 4 & 36,70 & 4 & 15.742 \\
PT & Reimont (13333) & 0,549 & 1,51 & 4 & 24,16 & 4 & 10.723 \\
\hline
\end{tabular}

Fonte: elaboração dos autores. Notas: A) Ordenação pela taxonomia adaptada e pela ordem decrescente do total de votos; B) Taxonomias:

1 - Concentrado/Dominante, 2 - Disperso/Dominante, 3 - Disperso/Compartilhado, 4 - Concentrado/Compartilhado; C).

Tabela 2. Quantitativos da classificação segundo as duas taxonomias.

\begin{tabular}{lcccc}
\hline \multirow{2}{*}{ Tipo } & \multicolumn{3}{c}{ Número de vereadores classificados em cada tipo } \\
\cline { 2 - 5 } & $\begin{array}{c}\text { Taxonomia } \\
\text { ames }\end{array}$ & $\begin{array}{c}\text { \% Taxonomia } \\
\text { ames }\end{array}$ & $\begin{array}{c}\text { Taxonomia } \\
\text { adaptada }\end{array}$ & $\begin{array}{c}\text { \% Taxonomia } \\
\text { adaptada }\end{array}$ \\
\hline Concentrado - Dominante (tipo 1) & 8 & 15,7 & 17 & 33,3 \\
Disperso - Dominante (tipo 2) & 8 & 15,7 & 10 & 19,7 \\
Disperso - Compartilhado (tipo 3) & 17 & 33,3 & 15 & 29,4 \\
Concentrado - Compartilhado (tipo 4) & 18 & 35,3 & 9 & 17,6 \\
Total & 51 & 100,0 & 51 & 100,0 \\
\hline
\end{tabular}

Fonte: elaboração dos autores.

Os índices de Moran dos partidos variam de 0,13 a 0,79 , o que mostra a inexistência de padrão ou de conjunto de padrões específicos dos partidos. Dentre os sete partidos mais votados no município, o PMDB, PSDB, PT e PTdoB apresentaram I de Moran acima da média, e os três outros (DEM, PV e PDT) mantiveram índices mais baixos, indicando pouca concentração espacial de votos. Nosso interesse é investigar se a votação dos candidatos eleitos, que pode informar sobre disputa territorial intrapartidária, mantém o padrão do partido, ou se as campanhas para o cargo de vereador, focadas na figura dos candidatos, levam a outro tipo de configuração.

\section{DEM}

O Democratas foi o partido que mais elegeu vereadores no pleito de 2008. A tabela dos indicadores (Tabela 4) revela uma tendência de concentração geoespacial de votos associada à forte conexão territorial da maioria de seus candidatos. Rosa Fernandes, Eider Dantas, Aloísio Freitas e Jorginho da SOS foram os candidatos do partido classificados 


\begin{tabular}{|c|c|c|c|c|c|c|}
\hline & Dominante & nexão forte & & Compartilh & onexãc & raca) \\
\hline \multirow{19}{*}{ Concentrado } & \multicolumn{3}{|c|}{$\begin{array}{l}\text { Com base em Ames, algumas características: } \\
\text { - São de reduto eleitoral, orientação paroquial } \\
\text { - Tem raízes familiares na política e economia } \\
\text { local } \\
\text { - Iniciaram carreira ou ocuparam cargo ligado ao } \\
\text { local, ou fazem acordo com caciques locais }\end{array}$} & \multicolumn{3}{|c|}{$\begin{array}{l}\text { Com base em Ames, algumas características: } \\
\text { - São candidatos dos bairros com maior número } \\
\text { de eleitores. } \\
\text { - Boa parte de sua votação é oriunda de bairros } \\
\text { onde compartilham o expressivo eleitorado com } \\
\text { muitos outros candidatos }\end{array}$} \\
\hline & \multicolumn{2}{|c|}{ Vereadores eleitos } & Votos & & & \\
\hline & \multicolumn{2}{|c|}{ 1. Lucinha (45620) } & \begin{tabular}{|l|}
68,799 \\
\end{tabular} & \multirow{2}{*}{\multicolumn{2}{|c|}{ Vereadores eleitos }} & Votos \\
\hline & \multicolumn{2}{|c|}{ 2. Rosa Fernandes (25625) } & 64,259 & & 1. Stepan Nercessian (23123) & 50,532 \\
\hline & \multicolumn{2}{|c|}{ 3. Alfredo Sirkis (43333) } & \begin{tabular}{|l|}
47,729 \\
2795 \\
\end{tabular} & \multicolumn{2}{|c|}{ 2. Clarissa Garotinho (15123) } & 42,062 \\
\hline & \multicolumn{2}{|c|}{ 4. Chiquinho Brazão (15101) } & \begin{tabular}{|l|}
37,845 \\
315,6 \\
\end{tabular} & \multicolumn{2}{|c|}{ 3. Marcio Pacheco (20010) } & 26,932 \\
\hline & \multicolumn{2}{|c|}{\begin{tabular}{|l} 
5. S. Ferraz $(15688)$ \\
6. Jorge Pereira $(70633)$
\end{tabular}} & \begin{tabular}{|l|}
34,540 \\
32,280 \\
\end{tabular} & \multicolumn{2}{|c|}{ 4. Jorge Braz (70070) } & 23,157 \\
\hline & \multicolumn{2}{|c|}{ 7. Aspásia Camargo (43123) } & 31,880 & \multicolumn{2}{|c|}{ 5. Patricia Amorim (45007) } & 21,140 \\
\hline & \multicolumn{2}{|c|}{ 8. Andrea Gouvêa Vieira (45123) } & 28,213 & \multicolumn{2}{|c|}{ 6. Carlo Caiado (25622) } & 19,042 \\
\hline & \multicolumn{2}{|c|}{ 9. Eider Dantas (25678) } & 27,718 & \multicolumn{2}{|c|}{ 7. Alexandre Cerruti (25123) } & 17,172 \\
\hline & \multicolumn{2}{|c|}{\begin{tabular}{|l|} 
10. Aloísio Freitas $(25640)$ \\
11. Jorge Felippe $(15800)$
\end{tabular}} & 26,545 & \multicolumn{2}{|c|}{ 8. Tânia Bastos (10789) } & 15,742 \\
\hline & \multirow{2}{*}{\multicolumn{2}{|c|}{\begin{tabular}{|l|} 
11. Jorge Felippe (15800) \\
12. Dr. Jairinho (20126) \\
\end{tabular}}} & 24,480 & \multirow{2}{*}{\multicolumn{2}{|c|}{ 9. Reimont (13333) }} & 10,723 \\
\hline & & & 23,880 & & & \\
\hline & \multicolumn{2}{|c|}{ 13. Carminha Jeronimo (70670) } & 22,068 & & & \\
\hline & \multirow{3}{*}{\multicolumn{2}{|c|}{\begin{tabular}{|l|} 
14. Paulo Pinheiro (23000) \\
15. João Mendes de Jesus (10123) \\
16. Jorginho da S.O.S (25105)
\end{tabular}}} & 20,936 & & & \\
\hline & & & 20,005 & & & \\
\hline & & & 18,557 & & & \\
\hline & \multicolumn{3}{|c|}{ 17. Eliomar Coelho (50000) } & & & \\
\hline & $\begin{array}{l}\text { Taxon. Ames } \\
(8)-15,7 \% \\
\end{array}$ & \multicolumn{2}{|c|}{$\begin{array}{c}\text { Taxon. Adaptada } \\
(17)-33,3 \% \\
\end{array}$} & $\begin{array}{l}\text { Taxon. Ames } \\
(18)-35,3 \% \\
\end{array}$ & $\begin{array}{r}\text { Taxo } \\
(9 \\
\end{array}$ & $\begin{array}{l}\text { Adaptada } \\
17,6 \% \\
\end{array}$ \\
\hline & $\begin{array}{l}\text { Com base em An } \\
\text { - Estabelecem rede } \\
\text { - Fazem acordos co } \\
\text { - Ocuparam postos } \\
\text { exerceram políticas } \\
\text { apoio nos bairros. } \\
\text { - Mesmo que receb } \\
\text { determinados bairr } \\
\text { aquele eleitorado. }\end{array}$ & $\begin{array}{l}\text { as caracte } \\
\text { e clientel } \\
\text { políticos } \\
\text { cos munic } \\
\text { ivas em pr } \\
\text { rotações e } \\
\text { identifica }\end{array}$ & $\begin{array}{l}\text { erísticas: } \\
\text { la difusas. } \\
\text { locais. } \\
\text { ipais e } \\
\text { ol do } \\
\text { m } \\
\text { ção com }\end{array}$ & $\begin{array}{l}\text { Com base em An } \\
\text { - Conseguem proje } \\
\text { ganham votos de } \mathrm{p} \\
\text { de muitos bairros. } \\
\text { - Base construída } \\
\text { de expressão muni } \\
\text { mobilização de vo } \\
\text { orientado por ques } \\
\text { (issue-oriented) }\end{array}$ & $\begin{array}{l}\text { as cara } \\
\text { do o m } \\
\text { ixas d } \\
\text { io de c: } \\
\text { tadual } \\
\text { co, rel } \\
\text { eresse }\end{array}$ & $\begin{array}{l}\text { erísticas: } \\
\text { icíípio, } \\
\text { eleitorado } \\
\text { gos políticos } \\
\text { u na } \\
\text { oso ou } \\
\text { minorias }\end{array}$ \\
\hline & & & & Vereadores eleito & & Votos \\
\hline & Vereadores eleit & & Votos & 1. Teresa Bergher & & 31,375 \\
\hline Disperso & 1. Vera Lins (11 & & 23,52 & 2. Carlos Bolsona & & 28,209 \\
\hline Dispenso & 2. Renato Mour & & 18,01 & 3. Dr. Carlos Edu & & $\frac{27,297}{25,382}$ \\
\hline & 3. João Cabral ( & & 17,79 & 5. Luiz Antonio C & 5001) & $\frac{25,582}{23,476}$ \\
\hline & 4. Professor Uós & & 14,28 & 6. Dr. Fernando $\mathrm{N}$ & 007) & $\frac{25,470}{19,762}$ \\
\hline & 5. Rubens Andra & & 11,98 & 7. Nereide Pedreg & & 19,562 \\
\hline & 6. Claudinho da & (27777) & 11,51 & 8. Liliam Sá (222 & & 15,742 \\
\hline & 7. Elton Babu (1 & & 11,27 & 9. Cristiane Brasi & & 14,583 \\
\hline & 8. Cristiano Girã & & 10,44 & 10. Roberto Mont & & 14,061 \\
\hline & 9. Ivanir de Mel & & 6,413 & 11. Jorge Manaia & & 14,040 \\
\hline & 10. Paulo Messi & & 5,201 & 12. Leonel Brizol & 345) & 12,988 \\
\hline & & & & 14. Bencardino (2 & & 5,361 \\
\hline & & & & 15. Marcelo Piuí & & 3,200 \\
\hline & $\begin{array}{l}\text { Taxon. Ames } \\
(8)-15,7 \%\end{array}$ & $\begin{array}{r}\text { Taxon. A } \\
(10)-1\end{array}$ & $\begin{array}{l}\text { daptada } \\
19,7 \%\end{array}$ & $\begin{array}{l}\text { Taxon. Ames } \\
(17)-33,3 \%\end{array}$ & Tax & $\begin{array}{l}\text { Adaptada } \\
-29,4 \%\end{array}$ \\
\hline
\end{tabular}

Fonte: Elaboração dos autores.

Figura 5. Quadro síntese da análise geoespacial dos padrões de votação dos vereadores.

na tipologia concentrado-dominante adaptada de Ames, indicando terem territórios eleitorais próprios e forte conexão com eles. Os demais se enquadram nos outros três tipos.
Os mapas de cluster dos candidatos (Figura 6) mostram a abrangência territorial do partido através das bases de seus eleitos. Os candidatos do DEM conseguem votos em praticamente todas as regiões 
Tabela 3. Total de votos e I de Moran dos Partidos.

\begin{tabular}{lcclcc}
\hline Partidos & $\begin{array}{c}\text { Total de votos } \\
\text { para vereador no } \\
\text { município }\end{array}$ & I de Moran & Partidos & $\begin{array}{c}\text { Total de votos } \\
\text { para vereador no } \\
\text { município }\end{array}$ & I de Moran \\
\hline DEM & 477.183 & 0,25 & PPS & 113.247 & 0,47 \\
PMDB & 343.173 & 0,48 & PCdoB & 110.260 & 0,16 \\
PSDB & 266.993 & 0,50 & PSB & 102.060 & 0,13 \\
PT & 201.663 & 0,32 & PTB & 86.863 & 0,28 \\
PV & 198.964 & 0,69 & PSDC & 82.713 & 0,18 \\
PTdoB & 175.154 & 0,79 & PTC & 72.485 & 0,36 \\
PDT & 174.220 & 0,15 & PSOL & 64.714 & 0,63 \\
PRB & 151.421 & 0,21 & PHS & 50.008 & 0,18 \\
PSC & 145.253 & 0,45 & PMN & 35.239 & 0,28 \\
PP & 140.584 & 0,48 & PRTB & 25.667 & 0,14 \\
PR & 135.928 & 0,24 & & & \\
\hline
\end{tabular}

Fonte: Elaboração própria a partir de dados do TSE.

Tabela 4. Indicadores dos Candidatos eleitos pelo DEM.

\begin{tabular}{llccccc}
\hline Partido & \multicolumn{1}{c}{ Candidatos eleitos } & $\begin{array}{c}\text { Concentração } \\
\text { (I de Moran) }\end{array}$ & $\begin{array}{c}\text { Conexão } \\
\text { Dominância }\end{array}$ & $\begin{array}{c}\text { Votos nos } \\
\text { com territórios } \\
\text { eleitorais }\end{array}$ & $\begin{array}{c}\text { territórios } \\
\text { eleitorais }\end{array}$ & $\begin{array}{c}\text { Votos no } \\
\text { município }\end{array}$ \\
\hline DEM & Rosa Fernandes (25625) & 0,715 & 2,70 & 68,23 & 43841 & 64259 \\
& Aloísio Freitas (25640) & 0,710 & 5,10 & 60,01 & 15930 & 26545 \\
& Jorginho da S.O.S. (25105) & 0,670 & 3,89 & 64,41 & 11952 & 18557 \\
& Eider Dantas (25678) & 0,579 & 2,89 & 53,99 & 14965 & 27718 \\
& Alexandre Cerruti (25123) & 0,563 & 1,59 & 46,49 & 7984 & 17172 \\
& Carlo Caiado (25622) & 0,558 & 2,70 & 44,37 & 8448 & 19042 \\
& João Cabral (25101) & 0,410 & 5,79 & 64,37 & 11451 & 17790 \\
& Tio Carlos (25008) & 0,333 & 2,52 & 30,98 & 7864 & 25382 \\
\hline
\end{tabular}

Fonte: Elaboração própria.

do município, com exceção da zona sul da cidade, revelando uma vantagem do partido na disputa territorial dos votos. No âmbito intrapartidário, dos 153 bairros, apenas em 21 há dois ou mais candidatos do partido com percentual alto de votos ${ }^{7}$.

\footnotetext{
Carlo Caiado disputa territórios com outros dois vereadores: Eider Dantas (Guaratiba, Campo Grande, Sepetiba, Vargem Grande, Pedra de Guaratiba, e Barra de Guaratiba) e Tio Carlos (Jacarepaguá, Camorim, Vargem Pequena e Recreio dos Bandeirantes). João Cabral e Jorginho da S.O.S. também dividem a concentração de votos em bairros comuns: Penha Circular, Olaria, Ramos, Maré, Bonsucesso, Del Castilho e Complexo do Alemão. O território da Penha Circular também é disputado pela vereadora Rosa Fernandes. A vereadora disputa ainda com Alexandre Cerruti os territórios eleitorais da Pavuna, Parque Columbia, Jardim América e Coelho Neto. A tabela dos indicadores do partido aponta que somente Rosa Fernandes, Aloísio Freitas, Jorginho da S.O.S. e Eider Dantas têm territórios eleitorais concentrados e com forte conexão, justamente os candidatos envolvidos na disputa.
}

\section{PMDB}

O PMDB elegeu cinco candidatos, todos com características de concentração espacial de votos (Tabela 5). Com exceção de Clarissa Garotinho (concentrado-compartilhado), os demais eleitos classificam-se na categoria concentrado-dominante, tendo alcançado de 59\% a $75 \%$ dos votos em seus territórios eleitorais, revelando que estes candidatos dependem de seus redutos eleitorais para se elegerem. Interessante observar que Clarissa Garotinho, a mais votada do partido, não concentrou seus votos nos seus territórios eleitorais, tendo sido bem votada em todo o município, provavelmente pelo apoio da base eleitoral do pai, o ex-governador Antony Garotinho.

Os mapas de cluster dos candidatos (Figura 7) mostram que não houve disputa intrapartidária, já que não há superposição territorial. Note-se que 
Alexandre Cerruti

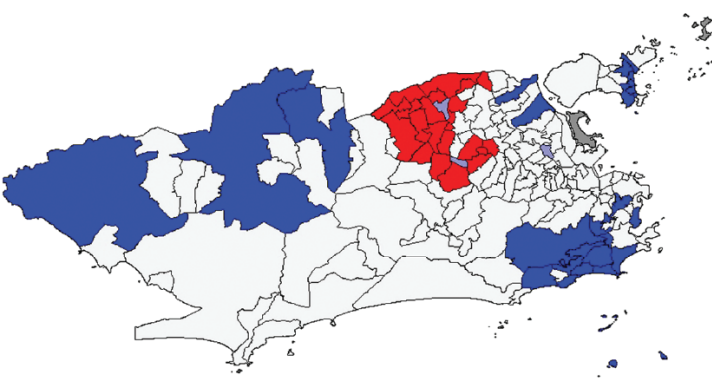

Carlo Caiado

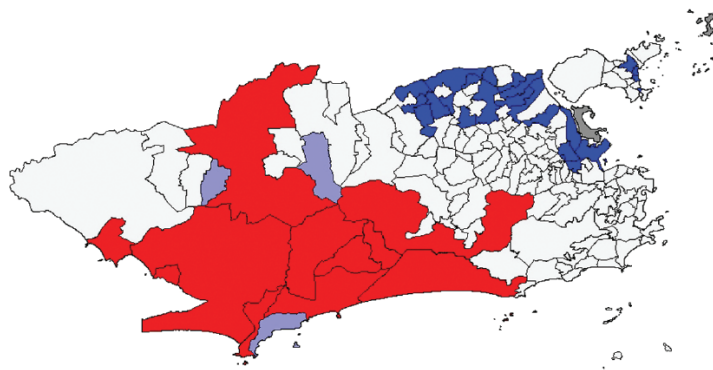

João Cabral

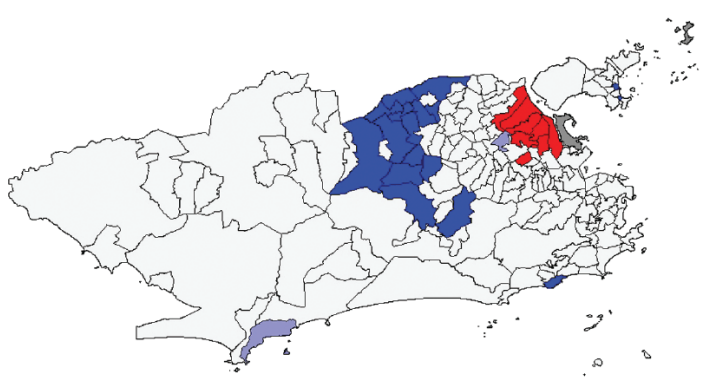

Rosa Fernandes

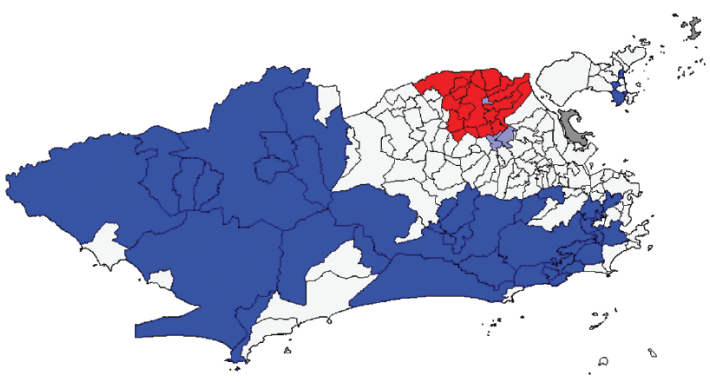

3
Aloísio Freitas

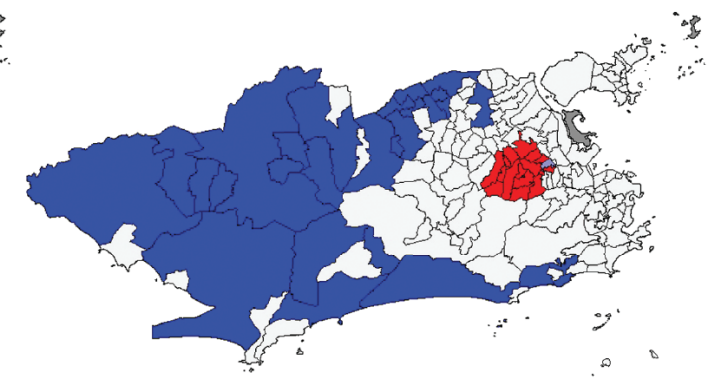

Eider Dantas

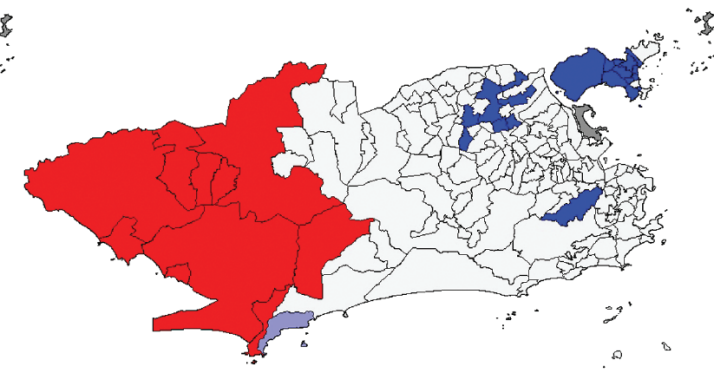

Jorginho da S.O.S

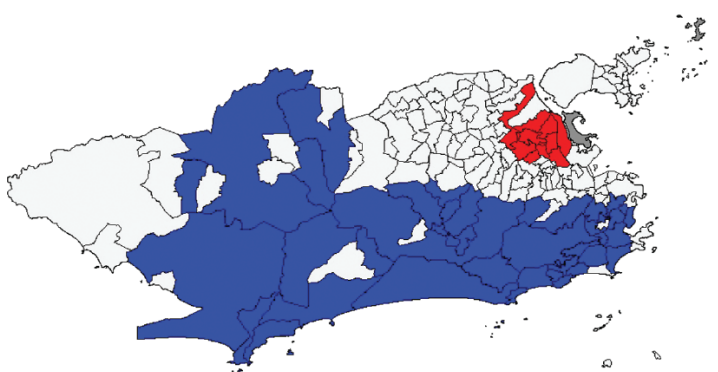

Tio Carlos

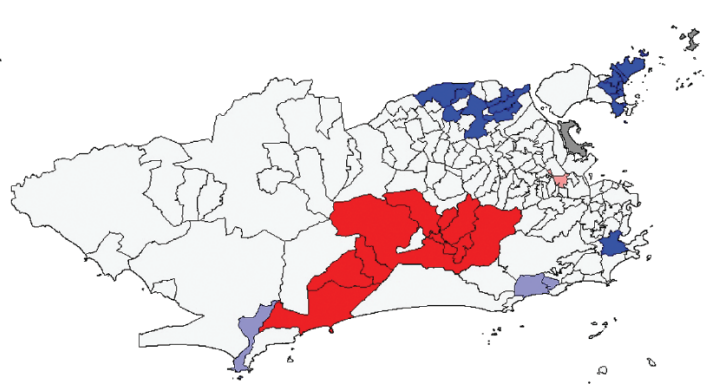
$\square$ Not significant
High-high
Low-low
Low-high
High-low
Neighborless

Figura 6. Mapas de Cluster dos vereadores eleitos do DEM (2008). 
Chiquinho Brazão e Jorge Felippe têm territórios eleitorais vizinhos que não se superpõe, indicando que o partido têm territórios eleitorais bem definidos localizados em diferentes áreas da cidade, basicamente na zona norte e na grande Jacarepaguá. O partido não tem representação na Zona Sul, Barra e Zona Oeste.

\section{PSDB}

O PSDB também elegeu cinco candidatos, dentre eles a candidata mais votada do município: Lucinha com 68799 votos (Tabela 6). Assim como Andrea Gouvêa Vieira, Lucinha classifica-se como concentrada-dominante na taxonomia adaptada de Ames, alcançando $85 \%$ dos votos nos seus territórios eleitorais, o que mostra que a candidata é altamente dependente de seu reduto eleitoral. Outra candidata com votos territorialmente concentrados é Patricia Amorim, no entanto seus votos são compartilhados, uma vez que o índice de dominância encontra-se abaixo da média. Luiz Antonio Guaraná e Teresa Bergher classificam-se como dispersos-compartilhados.

Portanto, os índices apontam que somente Lucinha e Andrea Gouvêa Vieira têm redutos eleitorais. Os mapas de cluster (Figura 8) mostram que a vereadora mais votada do município concentra seus votos na zona oeste da cidade e Andrea na zona sul. A disputa intrapartidária ocorreu somente entre Patricia Amorim e Luiz Antonio Guaraná nos bairros do Itanhangá e Barra da Tijuca, mas como são compartilhados e recebem mais de $50 \%$ de seus votos nos outros bairros, não consideramos que haja uma disputa efetiva entre os dois.

\section{PT}

O PT elegeu três vereadores (Tabela 7), dentre eles, Elton Babu que alcançou a marca de $73 \%$ de votos no seu território eleitoral associada a um I de Moran acima da média, o que o caracteriza como

Tabela 5. Indicadores dos Candidatos eleitos pelo PMDB.

\begin{tabular}{llccccc}
\hline Partido & \multicolumn{1}{c}{ Candidatos eleitos } & $\begin{array}{c}\text { Concentração } \\
\text { (I de Moran) }\end{array}$ & Dominância & $\begin{array}{c}\text { Conexão } \\
\text { com territórios } \\
\text { eleitorais }\end{array}$ & $\begin{array}{c}\text { Votos nos } \\
\text { territórios } \\
\text { eleitorais }\end{array}$ & $\begin{array}{c}\text { Votos no } \\
\text { município }\end{array}$ \\
\hline PMDB & Chiquinho Brazão (15101) & 0,614 & 10,83 & 75,35 & 28517 & 37845 \\
& S. Ferraz (15688) & 0,505 & 12,49 & 75,23 & 25989 & 34546 \\
& Clarissa Garotinho (15123) & 0,490 & 1,75 & 12,83 & 5395 & 42062 \\
& Jorge Felippe (15800) & 0,479 & 2,63 & 64,41 & 15768 & 24480 \\
& Professor Uóston (15633) & 0,421 & 4,11 & 58,98 & 8424 & 14282 \\
\hline
\end{tabular}

Fonte: Elaboração própria.
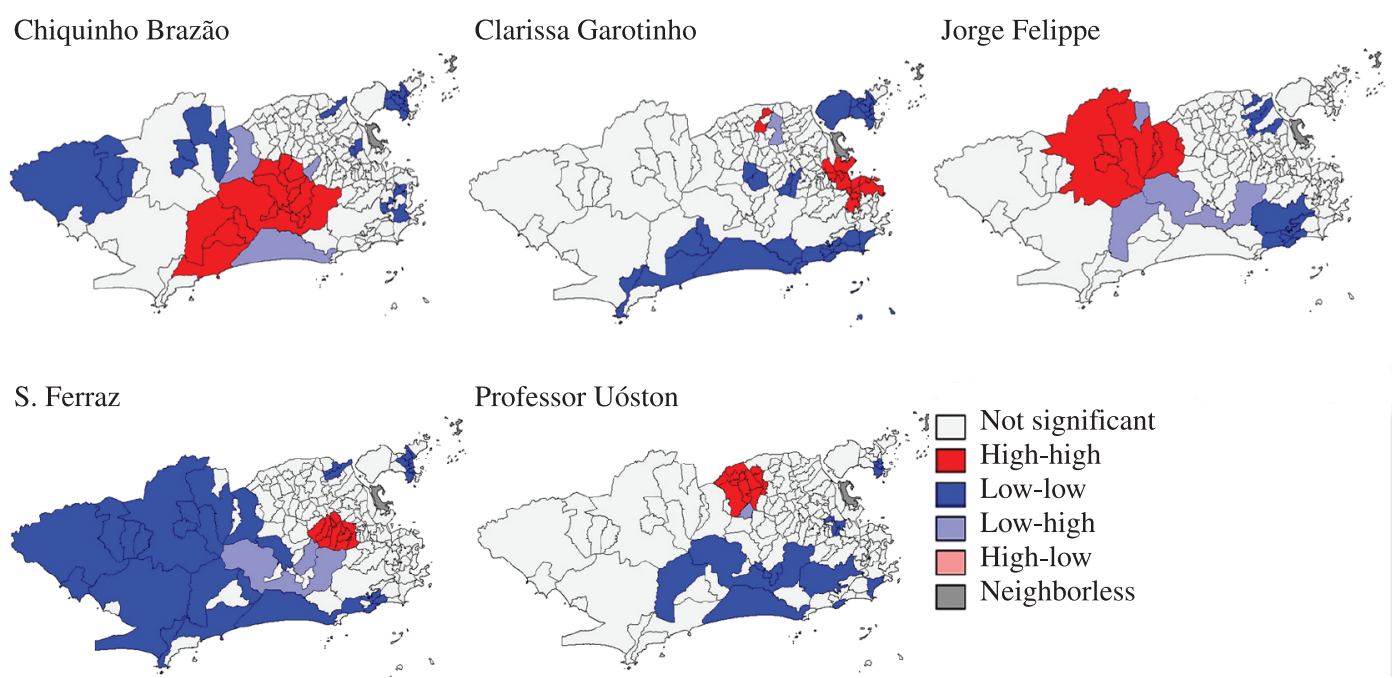

Professor Uóston

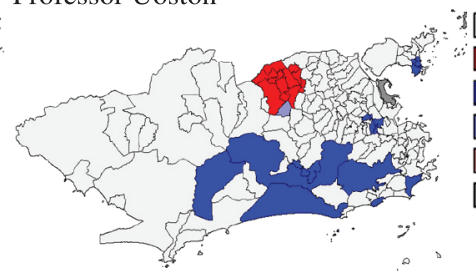

Not significant

High-high

Low-low

Low-high

High-low

Neighborless

Figura 7. Mapas de Cluster dos vereadores eleitos do PMDB (2008). 
concentrado-dominante. Reimont, classificado como concentrado-compartilhado, apresenta Moran acima da média e baixa dependência eleitoral de seu território. Enquanto Adilson Pires apresenta todos os indicadores abaixo de suas respectivas médias, indicando que seus votos dispersaram-se pelos bairros da cidade. A amostra é muito pequena para se dizer que há um perfil de candidatos associados à imagem do partido, embora com exceção de Elton Babu, os votos dos dois outros foram conquistados em todo o município.

Como há território eleitoral forte só na votação de Babu, não necessitariamos dos mapas para saber que dentre os eleitos pelo PT a disputa intrapartidária pelos mesmos territórios eleitorais não existe. Ainda assim, nos mapas da figura 9 observa-se que os votos de Babu se concentraram na zona oeste da cidade, na região de Santa Cruz e Guaratiba; Reimont concentrou
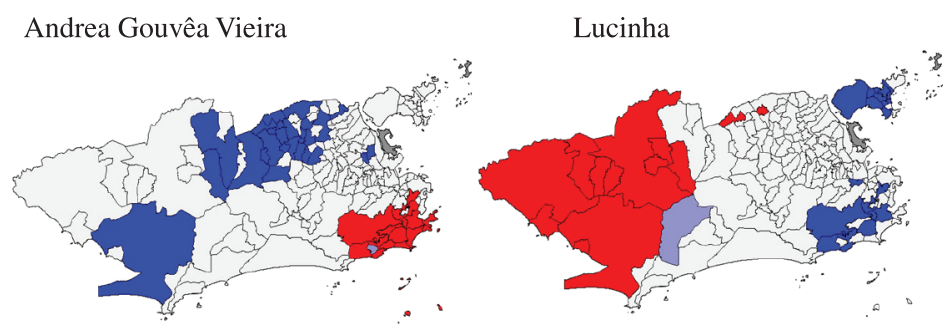

Luiz Antonio Guaraná

Patricia Amorim
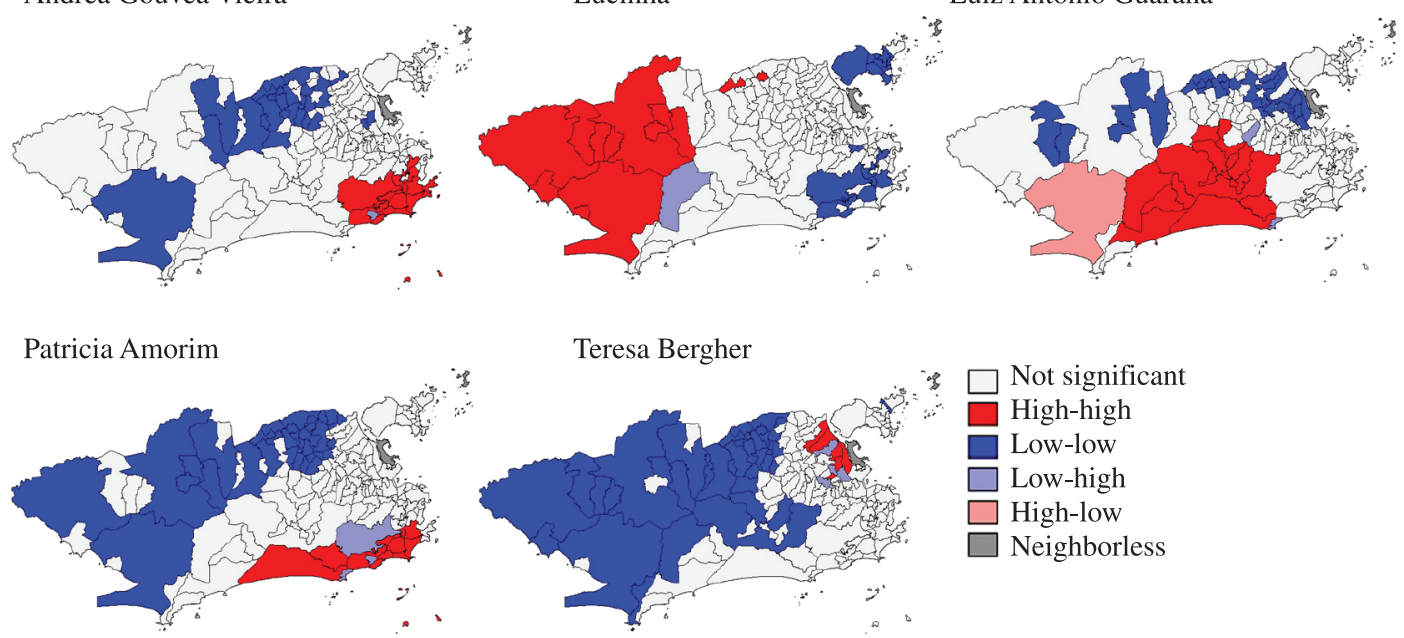

Figura 8. Mapas de Cluster dos vereadores eleitos do PSDB (2008).

Tabela 6. Indicadores dos Candidatos eleitos pelo PSDB.

\begin{tabular}{llccccc}
\hline Partido & \multicolumn{1}{c}{ Candidatos eleitos } & $\begin{array}{c}\text { Concentração } \\
\text { (I de Moran) }\end{array}$ & Dominância & $\begin{array}{c}\text { Conexão } \\
\text { com } \\
\text { territórios } \\
\text { eleitorais }\end{array}$ & $\begin{array}{c}\text { Votos nos } \\
\text { territórios } \\
\text { eleitorais }\end{array}$ & $\begin{array}{c}\text { Votos no } \\
\text { município }\end{array}$ \\
\hline PSDB & Andrea Gouvêa Vieira (45123) & 0,710 & 4,66 & 61,46 & 17339 & 28213 \\
& Lucinha (45620) & 0,687 & 12,02 & 84,58 & 58192 & 68799 \\
& Patricia Amorim (45007) & 0,517 & 2,29 & 46,95 & 9926 & 21140 \\
& Luiz Antonio Guaraná (45001) & 0,476 & 2,04 & 44,64 & 10479 & 23476 \\
& Teresa Bergher (45245) & 0,235 & 8,07 & 47,98 & 15055 & 31375 \\
\hline
\end{tabular}

Fonte: Elaboração própria.

Tabela 7. Indicadores dos Candidatos eleitos pelo PT.

\begin{tabular}{llccccc}
\hline Partido & Candidatos eleitos & $\begin{array}{c}\text { Concentração } \\
\text { (I de Moran) }\end{array}$ & Dominância & $\begin{array}{c}\text { Conexão } \\
\text { com territórios } \\
\text { eleitorais }\end{array}$ & $\begin{array}{c}\text { Votos nos } \\
\text { territórios } \\
\text { eleitorais }\end{array}$ & $\begin{array}{c}\text { Votos no } \\
\text { município }\end{array}$ \\
\hline PT & Reimont (13333) & 0,549 & 1,51 & 24,16 & 2591 & 10723 \\
& Elton Babu (13444) & 0,454 & 3,91 & 72,96 & 8229 & 11279 \\
& Adilson Pires (13620) & 0,025 & 1,42 & 8,80 & 1017 & 11555 \\
\hline
\end{tabular}

Fonte: Elaboração própria. 
votos na região da Tijuca e Adilson Pires em Bangu, Senador Camará e Padre Miguel.

\section{PDT}

Dos eleitos pelo PDT (Tabela 8), nenhum deles apresentou perfil de concentração espacial de votos, sugerindo que a relação dos eleitores com os candidatos é permeada pelo partido, pois não há um candidato que se destaque em áreas pontuais da cidade. Isto é coerente com a atuação histórica do partido no município e no estado do Rio de Janeiro. Esse perfil parece o oposto daquele que caracteriza o Democratas.

Os mapas da figura 10 apresentam as regiões onde os candidatos foram mais votados. Não há de se falar em territórios eleitorais dos candidatos, já que os votos do partido foram recebidos em todo município.
Mesmo assim, não houve disputas entre os candidatos pelos territórios eleitorais, ainda que fracos.

\section{PTdoB}

Com três candidatos eleitos (Tabela 9), o PTdoB destacou-se como o sexto partido mais votado no município. Seus candidatos foram eleitos com alta concentração territorial de votos. Jorge Pereira aparece em primeiro lugar dentre os candidatos de votação territorial mais concentrada, com alta dependência eleitoral de seu território e a maior dominância média alcançada, preenchendo com folga, todos os requisitos para caracterizar-se como concentrado-dominante na taxonomia. Carminha Jerominho também se enquadra nesta classificação, chegando a concentrar $86,2 \%$ de seus votos no seu reduto eleitoral. Jorge Braz é
Adilson Pires

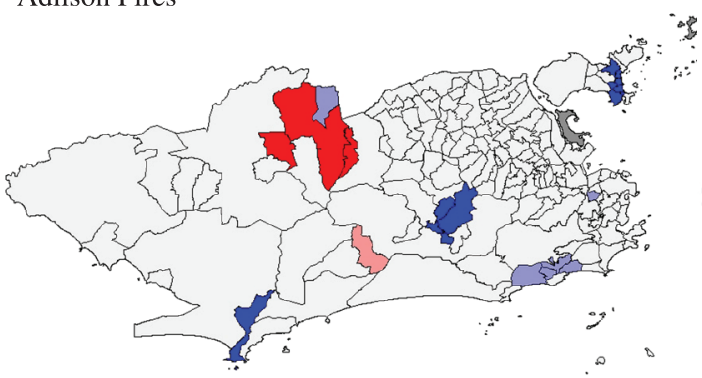

Elton Babu

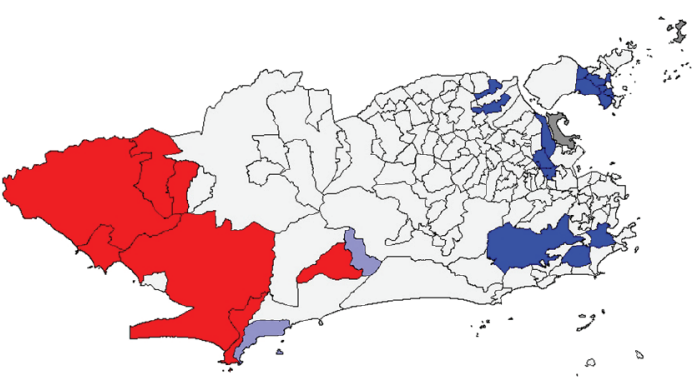

Not significant

High-high

Low-low

Low-high

High-low

Neighborless

Figura 9. Mapas de Cluster dos vereadores eleitos do PT (2008).

Tabela 8. Indicadores dos Candidatos eleitos pelo PDT.

\begin{tabular}{llccccc}
\hline Partido & Candidatos eleitos & $\begin{array}{c}\text { Concentração } \\
\text { (I de Moran) }\end{array}$ & Dominância & $\begin{array}{c}\text { Conexão } \\
\text { com territórios } \\
\text { eleitorais }\end{array}$ & $\begin{array}{c}\text { Votos nos } \\
\text { territórios } \\
\text { eleitorais }\end{array}$ & $\begin{array}{c}\text { Votos no } \\
\text { município }\end{array}$ \\
\hline PDT & Leonel Brizola Neto (12345) & 0,398 & 0,53 & 17,45 & 2267 & 12988 \\
& Jorge Manaia (12580) & 0,358 & 0,51 & 26,16 & 3673 & 14040 \\
& Nereide Pedregal (12787) & 0,157 & 7,70 & 32,44 & 6346 & 19562 \\
\hline
\end{tabular}

Fonte: Elaboração própria. 
classificado como concentrado-compartilhado, mas alcança quase $50 \%$ de votos nos seus territórios.

Os mapas de cluster (Figura 11) mostram que os votos de Jorge Pereira concentraram-se na Ilha do Governador. A concentração de Carminha Jerominho localizou-se na zona oeste e Jorge Braz na zona norte, na região que compreende Inhaúma, Bonsucesso, São Cristóvão, Del Castilho entre outros. Não houve disputa intrapartidária pelos mesmos territórios eleitorais.

\section{PV}

Os dois principais candidatos eleitos pelo Partido Verde (Tabela 10) apresentam uma tendência à concentração espacial de votos e se enquadram na classificação concentrado-dominante de Ames. Aspásia e Sirkis têm I de Moran de aproximadamente,
0,70 e percentual de votos em torno de $55 \%$ nos territórios eleitorais, perfis bastante parecidos, sendo Aspásia uma candidata mais concentrada e mais dependente do seu reduto eleitoral na comparação com Sirkis. O terceiro candidato, Paulo Messina, eleito com muito menos votos, apresenta I de Moran abaixo da média, e entra na classificação adaptada como disperso-dominante, devido ao alto percentual de votos alcançado no seu reduto eleitoral.

Os mapas de cluster (Figura 12) mostram que Aspásia e Sirkis têm territórios eleitorais superpostos, indicando disputa intrapartidária forte de votos, localizada na zona sul da cidade. Paulo Messina concentra votos na zona norte, nas regiões da Penha, Bonsucesso, e outros. Apesar da disputa, os dois candidatos são capazes de se eleger.
Jorge Manaia

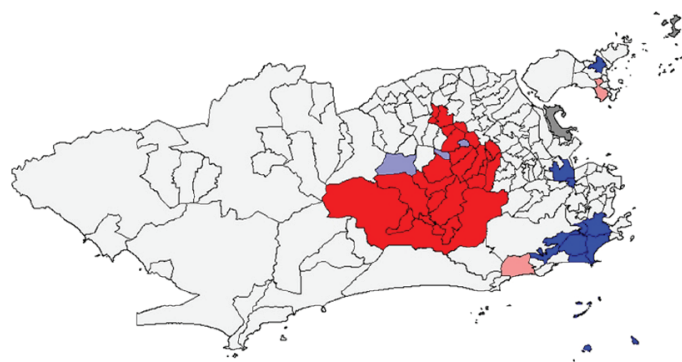

Leonel Brizola Neto

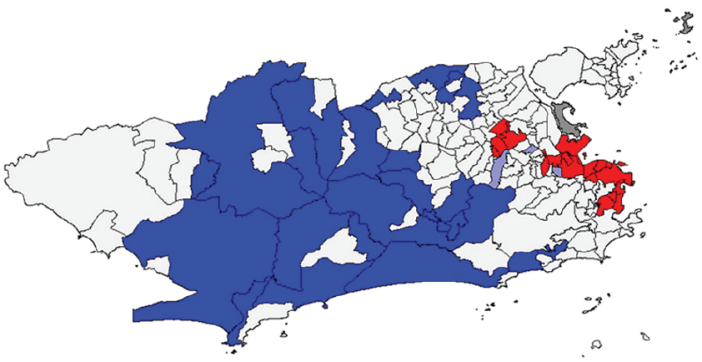

Nereide Pedregal

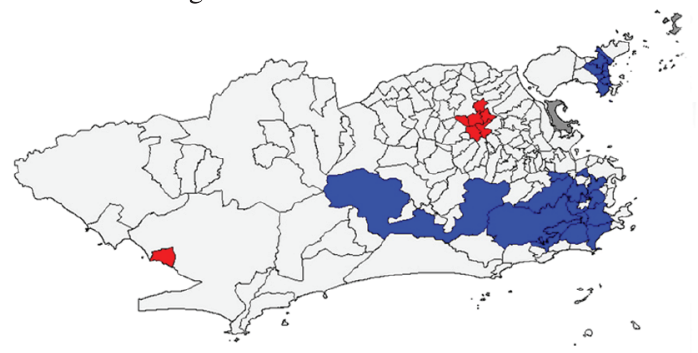

$\square$ Not significant
$\square$ High-high
$\square$ Low-low
$\square$ Low-high
$\square$ High-low
$\square$ Neighborless

Figura 10. Mapas de Cluster dos vereadores eleitos do PDT (2008).

Tabela 9. Indicadores dos Candidatos eleitos pelo PTdoB.

\begin{tabular}{llccccc}
\hline Partido & \multicolumn{1}{c}{ Candidatos eleitos } & $\begin{array}{c}\text { Concentração } \\
\text { (I de Moran) }\end{array}$ & Dominância & $\begin{array}{c}\text { Conexão } \\
\text { com territórios } \\
\text { eleitorais }\end{array}$ & $\begin{array}{c}\text { Votos nos } \\
\text { territórios } \\
\text { eleitorais }\end{array}$ & $\begin{array}{c}\text { Votos no } \\
\text { município }\end{array}$ \\
\hline PTdoB & Jorge Pereira (70633) & 0,919 & 22,20 & 81,63 & 27166 & 33280 \\
& Jorge Braz (70070) & 0,703 & 1,98 & 48,50 & 11231 & 23157 \\
& Carminha Jerominho (70670) & 0,482 & 7,17 & 86,19 & 19021 & 22068 \\
\hline
\end{tabular}

Fonte: Elaboração própria. 

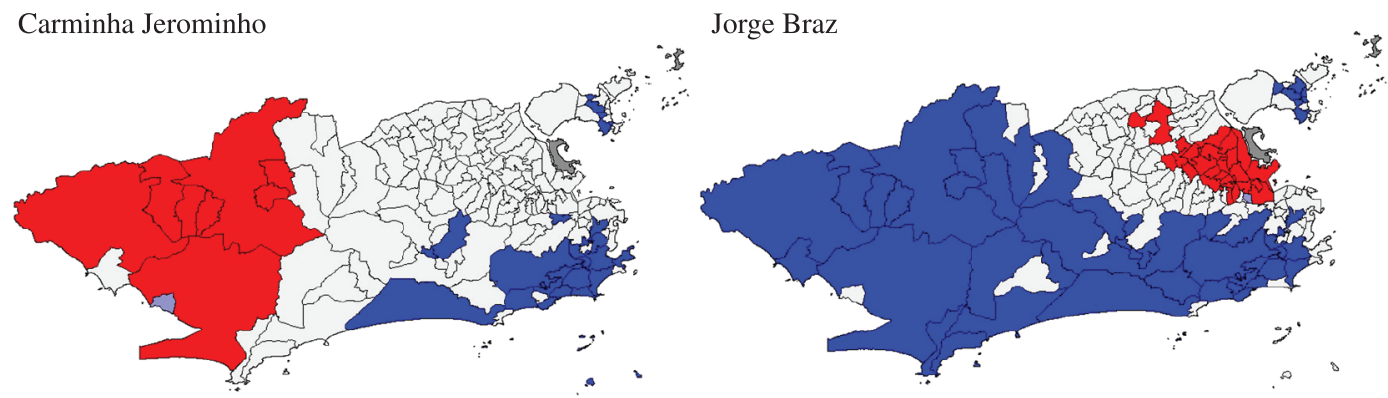

Jorge Pereira
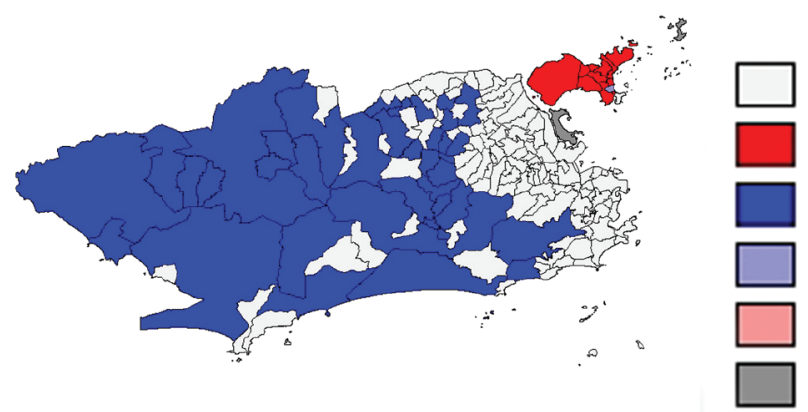

Not significant

High-high

Low-low

Low-high

High-low

Neighborless

Figura 11. Mapas de Cluster dos vereadores eleitos do PTdoB (2008).
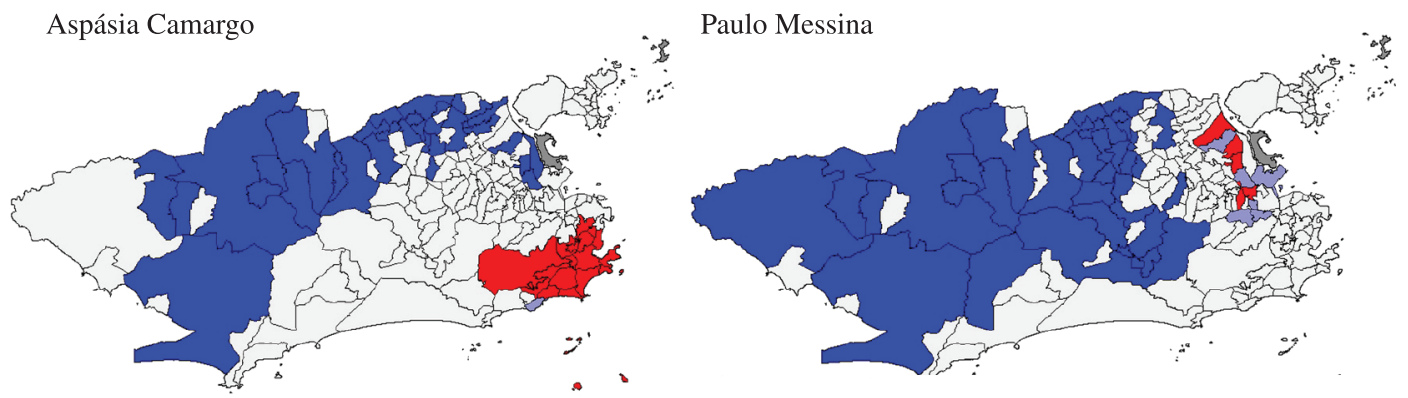

Sirkis
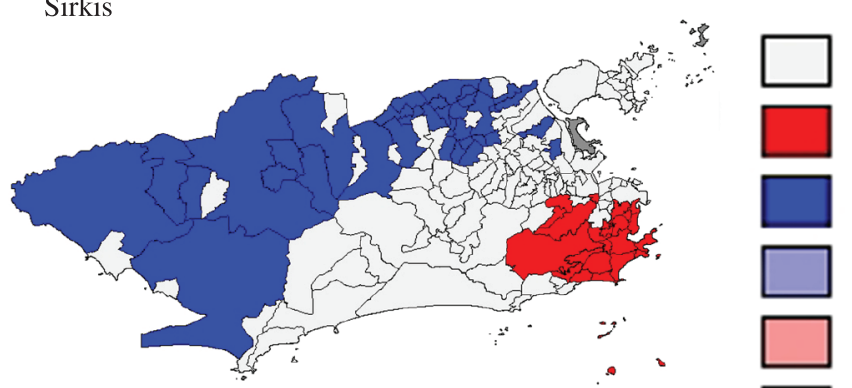

Not significant

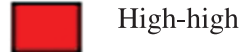

$\square$ Low-low

$\square$ Low-high

High-low

Neighborless

Figura 12. Mapas de Cluster dos vereadores eleitos do PV (2008). 
Tabela 10. Indicadores dos Candidatos eleitos pelo PV.

\begin{tabular}{llccccc}
\hline Partido & Candidatos eleitos & $\begin{array}{c}\text { Concentração } \\
\text { (I de Moran) }\end{array}$ & Dominância & $\begin{array}{c}\text { Conexão } \\
\text { com territórios } \\
\text { eleitorais }\end{array}$ & $\begin{array}{c}\text { Votos nos } \\
\text { territórios } \\
\text { eleitorais }\end{array}$ & $\begin{array}{c}\text { Votos no } \\
\text { município }\end{array}$ \\
\hline PV & Aspásia (43123) & 0,761 & 3,83 & 56,88 & 18134 & 31880 \\
& Alfredo Sirkis (43333) & 0,696 & 3,71 & 54,74 & 26127 & 47729 \\
& Paulo Messina (43001) & 0,177 & 1,58 & 52,62 & 2737 & 5201 \\
\hline
\end{tabular}

Fonte: Elaboração própria.

\section{Considerações Finais}

Há padrões espaciais na votação dos vereadores eleitos em 2008 na megacidade do Rio de Janeiro, e é possível classificá-los. O exercício que fizemos mostra, entretanto, que a construção de uma taxonomia para candidatos de eleições proporcionais não é uma equação simples. Há a questão do distrito de grande magnitude e a identificação dos distritos informais, a combinação entre o personalismo e as estratégias partidárias, e várias outras discussões de natureza conceitual e metodológica.

Uma classificação ou taxonomia pode ser pensada com várias combinações de indicadores. Nós selecionamos três, e os classificamos de acordo com um critério estatístico. Optamos por baseá-lo na média, mas poderia ser pela mediana ou por outro critério. Chegamos a algo que se aproxima da taxonomia de Ames (2003), mas é preciso avançar para identificar na série histórica se estes padrões se mantêm, e se permanecem em iguais proporções. Se tais padrões podem ser associados a um determinado tipo de atuação parlamentar ou não.

Incluímos o que chamamos de indicador de conexão com os territórios eleitorais, dado pelo percentual de votos que o candidato obtém nos bairros que constituem seu reduto. Este indicador mostrou que, dos 51 vereadores, independente da taxonomia, $53 \%$ (27vereadores) obtém mais de metade de seus votos de um grupamento pequeno de bairros que constitui seu território eleitoral. A análise de Moran local nos permitiu identificar os territórios eleitorais, e a partir daí, o indicador de conexão com este território. Obter mais de 50\% dos votos em poucos bairros vizinhos é um incentivo e tanto para manter uma boa conexão com esta base eleitoral. Como eles o fazem, só avançando na pesquisa para saber se há algum tipo de paroquialismo e se o modus operandi muda conforme as características do candidato, do partido ou da região.

Há disputa intrapartidária? A considerar as críticas ao sistema representativo de lista aberta, caracterizado como permissivo ao admitir disputas intrapartidárias, a análise dos partidos foi desenvolvida para investigar esta questão. A princípio parece que há muito pouca competição. A partir da avaliação dos mesmos indicadores de concentração espacial dos votos, dominância média nos municípios e grau de conexão que os candidatos têm com seus territórios, e dos mapas de cluster, apontamos a tendência geral dos sete partidos mais votados. Os índices sugerem que predominam os candidatos de perfis de concentração espacial de votos no DEM, PMDB, PSDB, PTdoB e PV, enquanto no PT e PDT há uma tendência mais dispersa. Observou-se tendências, pois o número dos candidatos eleitos por partido é diferente, o que impossibilita a comparação.

Os mapas de cluster e o respectivo cadastro dos bairros dos territórios eleitorais permitiram analisar a superposição de territórios dos vereadores de um mesmo partido. Dentre os sete partidos, em três deles houve disputas de territórios entre candidatos. $\mathrm{O}$ Democratas foi o que mais apresentou superposição de territórios eleitorais dentre os candidatos que concorreram pela legenda. Deve-se ter em conta que o partido também é o maior em número de candidatos eleitos. No PSDB, identificou-se alguma disputa por dois bairros, e no PV há a superposição territorial dos dois candidatos mais votados, que competem praticamente nos mesmos bairros da zona sul. Nos demais não foi encontrada disputa intrapartidária.

Esses resultados não são conclusivos e suficientes para responder à pergunta inicial, uma vez que não encontramos padrões passíveis de classificação. A investigação das disputas intrapartidárias foi proposta com o intuito exploratório e para testar a aplicabilidade do índice de autocorrelação espacial para tal fim, na tentativa de contribuir com as discussões sobre o sistema eleitoral de lista aberta, mais dirigida aos deputados federais. Há que se levar em conta que a análise contemplou apenas os eleitos, e que focalizamos os sete partidos mais votados. Possivelmente uma investigação abrangendo toda a gama de candidatos ao cargo de vereador, e outro arranjo metodológico, menos descritivo e mais baseado em estatística e econometria espacial 
seja mais adequado e conclusivo. Acredita-se que assim chegaríamos a conclusões mais efetivas acerca das disputas intrapartidárias, além de obter pistas importantes sobre o papel dos partidos na articulação das candidaturas e no processo eleitoral como um todo.

\section{Referências}

Ames, Barry. 2003. Os entraves da democracia no Brasil. Rio de Janeiro: FGV.

Anselin, Luc. 1999. Spatial Econometrics (Working Paper). Disponível em: http://www.csiss.org/aboutus/ presentations/.

Anselin, Luc. 2003. GeoDa 0.9 User's Guide. UrbanaChampaign: University of Illinois. Disponível em: http://geodacenter.org/downloads/pdfs/geoda093.pdf

Anselin, Luc. 2005. Exploring Spatial Data with GeoDaTM: A Workbook. Disponível em: http:// geodacenter.asu.edu/system/files/geodaworkbook.pdf

Câmara, Gilberto; Carvalho, Marília Sá; Cruz, Oswaldo Gonçalves; Correa, Virginia. 2002. Análise espacial de áreas. In Suzana Druck Fucks, Marília Sá Carvalho, Gilberto Câmara, Antonio Miguel Vieira Monteiro (orgs). Análise espacial de dados geográficos. São José dos Campos, SP: INPE. Disponível em: http:// urlib.net/sid.inpe.br/sergio/2004/10.07.15.04

Carvalho, Nelson Rojas de. 2009. Geografia política das eleições congressuais: a dinâmica de representação das áreas urbanas e metropolitanas no Brasil. Caderno Metrópole, 11(22): 367-384.
Carvalho, Nelson Rojas de. 2003. E no início eram as bases: Geografia política do voto e do comportamento legislativo no Brasil. Rio de Janeiro: Revan.

Instituto Pereira Passos - IPP. 2012. Consulta ao Armazém de Dados. Disponível em www.armazemdedados.rio. rj.gov.br/. Acesso em: 23 jan 2012.

Martins, Paulo Cesar. 2011. Desigualdades socioespaciais no Município do Rio de Janeiro: um foco na Região Administrativa de Vigário Geral. Dissertação de Mestrado, Rio de Janeiro: ENCE.

Nicolau, Jairo. 2006. O Sistema Eleitoral de Lista Aberta no Brasil. Dados, 49(4): 689-720. http://dx.doi. org/10.1590/S0011-52582006000400002

O'Loughlin, John. 2002. The Electoral Geography of Weimar Germany: Exploratory Spatial Data Analyses (ESDA) of Protestant Support for the Nazi Party. Political Analysis, 10(3): 217-243. http://dx.doi. org/10.1093/pan/10.3.217

Smith, Michael J., Goodchild, Michael F. e Longley, Paul A. 2007. Geospatial Analysis: A Comprehensive Guide to Principles, Techniques and Software Tools. Winchelsea, UK: The Winchelsea Press. Disponível em: http://www.spatialanalysisonline.com/

Terron, Sonia. 2009. A Composição de Territórios Eleitorais no Brasil: Uma Análise das Votações de Lula (1989 - 2006). Tese de Doutorado. Rio de Janeiro: IUPERJ. Disponível em: http://uerj.academia.edu/ SoniaTerron e http://www.opiniaopublica.ufmg.br/ biblioteca_detalhe.php?tema=el\&\&tipo=teses

Tribunal Superior Eleitoral - TSE. 2008. Estatística do Eleitorado - Consulta Quantitativo. Município do Rio de Janeiro, Outubro/2008. Disponível em: <http:// www.tse.jus.br/eleicoes/estatisticas-do-eleitorado/ quantitativo-do-eleitorado/consulta-quantitativo $>$. 